\title{
Reliability Evaluation of Smart Microgrids Considering Cyber Failures and Disturbances under Various Cyber Network Topologies and Distributed Generation's Scenarios
}

\author{
Mehrdad Aslani, Hamed Hashemi-Dezaki * (D) and Abbas Ketabi (D) \\ Department of Electrical and Computer Engineering, University of Kashan, 6 km Ghotbravandi Blvd, \\ Kashan 8731753153, Iran; m.aslani@grad.kashanu.ac.ir (M.A.); aketabi@kashanu.ac.ir (A.K.) \\ * Correspondence: hamed.hashemi@kashanu.ac.ir; Tel.: +98-31-5591-3483
}

check for

updates

Citation: Aslani, M.;

Hashemi-Dezaki, H.; Ketabi, A.

Reliability Evaluation of Smart

Microgrids Considering Cyber

Failures and Disturbances under

Various Cyber Network Topologies and Distributed Generation's

Scenarios. Sustainability 2021, 13, 5695

https://doi.org/10.3390/su13105695

Academic Editors: Ali Sohani and Hoseyn Sayyaadi

Received: 25 April 2021

Accepted: 17 May 2021

Published: 19 May 2021

Publisher's Note: MDPI stays neutral with regard to jurisdictional claims in published maps and institutional affiliations.

Copyright: (c) 2021 by the authors. Licensee MDPI, Basel, Switzerland. This article is an open access article distributed under the terms and conditions of the Creative Commons Attribution (CC BY) license (https:/ / creativecommons.org/licenses/by/ $4.0 /)$.
Abstract: Smart microgrids (SMGs), as cyber-physical systems, are essential parts of smart grids. The SMGs' cyber networks facilitate efficient system operation. However, cyber failures and interferences might adversely affect the SMGs. The available studies about SMGs have paid less attention to SMGs' cyber-physical features compared to other subjects. Although a few current research works have studied the cyber impacts on SMGs' reliability, there is a research gap about reliability evaluation simultaneously concerning all cyber failures and interferences under various cyber network topologies and renewable distributions scenarios. This article aims to fill such a gap by developing a new Monte Carlo simulation-based reliability assessment method considering cyber elements' failures, data/information transmission errors, and routing errors under various cyber network topologies. Considering the microgrid control center (MGCC) faults in comparion to other failures and interferences is one of the major contributions of this study. The reliability evaluation of SMGs under various cyber network topologies, particularly based on an MGCC's redundancy, highlights this research's advantages. Moreover, studying the interactions of uncertainties for cyber systems and distributed generations (DGs) under various DG scenarios is another contribution. The proposed method is applied to a test system using actual historical data. The comparative test results illustrate the advantages of the proposed method.

Keywords: smart microgrid (SMG); reliability evaluation; cyber-physical system (CPS); cyber elements' failures; microgrid control center (MGCC)'s faults; information transmission's quality; cyber network topologies; uncertainty; renewable distributed generations (DGs); Monte Carlo simulation (MCS)

\section{Introduction}

The microgrid (MG) concept has received a great deal of attention because of its contribution to emission mitigation and sustainable development [1-3]. The cyber system, including communication networks, information technologies, and smart monitoring/control systems, boosts the MGs' reliability, efficiency, and technoeconomic aspects [4,5]. However, the cyber system impacts, such as other uncertainties, might influence smart grids and MGs' reliability [6-8]. Although the impacts of the uncertainties in the output power of renewable distributed generations (DGs) on MGs' reliability have been studied in the literature, such as in [9-11], less attention has been paid to the eventual cyber-power uncertainties and interdependencies of cyber-power MGs (CPMGs).

The Monte Carlo simulation (MCS) methods could help evaluate smart grids /MGs' reliability considering cyber-power interdependencies and other stochastic behaviors [12]. The sequential MCS has been adopted to quantify the MGs' reliability due to frequency control issues, while cyber failures have been of concern in [13]. In [14,15], the MCSbased smart grid's reliability evaluation methods considering the impacts of direct and indirect cyber-power interdependencies have been reported, respectively. Wang et al. [16] 
evaluated the effects of data transmission errors, latency, cyber element defects, and routing errors on MG reliability using the MCS. Although the impacts of most essential parameters have been addressed in [16], the defects of the MG control center (MGCC) have not been considered. In addition, the CPMGs' reliability and interaction of cyber and renewable DG uncertainties under various DG scenarios has not been studied in [16].

The computation time of MCS-based methods affects their effectiveness, particularly for reliability-oriented short-term operational decisions. Therefore, some research works have been devoted to developing non-MCS methods to speed up the smart grid/CPMG's reliability assessment. Falahati et al. [17] reported a new probability table (P-Table)-based reliability assessment approach that considers direct cyber-power interdependencies, while other system uncertainties, such as stochastic behaviors of renewable DGs' output power, have not been considered. The indirect cyber-power interdependencies due to malfunctions of monitoring and protection systems have been examined in [18]. Zhu et al. [19] presented an analytical method that uses complex network theory to investigate the effect of communication network interruptions and failures on smart grid reliability. The reliability of each communication device and packet transmission delay has been researched in [19]. In most non-MCS reliability evaluation methods for CPMGs, the renewable DGs uncertainties have not been researched due to their limitations compared to MCS-based ones. In a few available studies, such as [20], both the DGs and cyber-power uncertainties have been considered using non-MCS methods. Barani et al. [20] have studied the uncertainty of renewable DGs along with communication technologies and cyber networks in MGs' reliability evaluation. Although cyber component failure impacts have been concerned in [20], various parts of networks and communication technologies, such as data transmission delay and data transfer errors, have not been considered.

In Table 1, a summary of the literature review in the area of smart grid and MGs' reliability evaluation considering the cyber-physical challenges is presented. In light of the literature review, there is a research gap about developing a reliability evaluation method for CPMGs, which simultaneously concerns all cyber challenges, particularly the failures of MGCC. This study aims to respond to such a research gap by proposing a new MCS-based reliability evaluation method. Proposing a new method considering both uncertainties of the cyber system and renewable DGs is the major contribution of this research. Developing a new MCS-based reliability assessment method for CPMGs using the theory graph concepts based on cyber-physical interdependencies is another contribution of this study. Moreover, the CPMGs and the interactions of different cyber uncertainties with DGs' uncertainties under various DG scenarios would be studied.

Comparing available MCS-based and non-MCS reliability assessment methods infers that the MCS-based ones could be more effective for precisely studying all uncertainties. Hence, the MCS has been selected in this research. However, the non-MCS methods that considers all cyber and physical uncertainties could be developed in future works.

The major contributions of this research are listed as follows:

- Proposing a new MCS-based reliability evaluation of CPMGs that considers all cyber faults and interruptions, i.e., information transmission errors, routing errors, and delay of information channels;

- Considering the MGCC faults' impacts on CPMG's reliability;

- Simulating the uncertainties of the physical system of CPMG, e.g., stochastic behaviors of wind turbine (WT) and photovoltaic (PV)outputs;

- $\quad$ Studying the CPMG's reliability under different cyber network topologies, including cyber network topologies with the redundancies of the MGCC;

- An analysis of the CPMG's reliability under various DG scenarios;

- Sensitivity analyses to gain insight into how the cyber failures and interruptions might affect the CPMG's reliability.

The proposed method is compared to available ones such as in [16], which has not addressed the MGCC faults. The test results illustrate the advantages of the proposed method. In addition, the proposed method is studied under different DG scenarios, 
including PV and WT DGs. The sensitivity analyses are performed to obtain insight into how the changes in physical and cyber characteristics might affect the CPMGs' reliability.

The organization of the rest of this paper is as follows: Section 2 presents the CPMG's control/energy management structure and different cyber-power interdependencies on system reliability, Section 3 introduces the proposed reliability evaluation method and reliability modeling of CPMGs' subsystems, Section 4 presents the simulation results and discussions are given, and, finally, the conclusion is reported in Section 5.

Table 1. A summary of the literature review on SMG reliability evaluation.

\begin{tabular}{|c|c|c|c|c|c|c|c|c|c|c|}
\hline 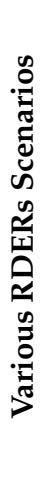 & 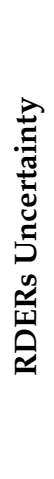 & 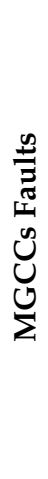 & 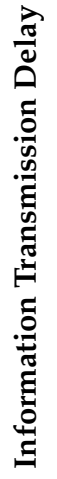 & 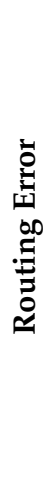 & 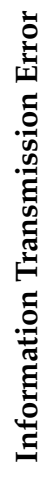 & 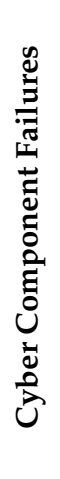 & 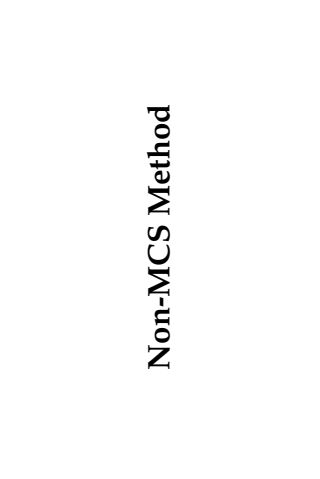 & 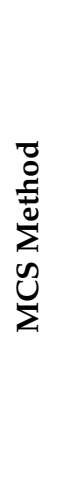 & ‡્ર & 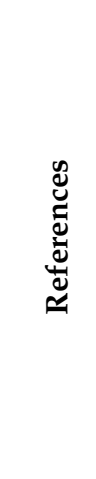 \\
\hline $\mathbf{x}$ & $\mathbf{x}$ & $\mathbf{x}$ & $x$ & $x$ & $x$ & $\checkmark$ & Markov Chain Model & $x$ & 2012 & [17] \\
\hline $\mathbf{x}$ & $\mathbf{x}$ & $\mathbf{x}$ & $\mathbf{x}$ & $\mathbf{x}$ & $\mathbf{x}$ & $\checkmark$ & P-Table & $\mathbf{x}$ & 2014 & [18] \\
\hline $\mathbf{x}$ & $\mathbf{x}$ & $\mathbf{x}$ & $\mathbf{x}$ & $\mathbf{x}$ & $\mathbf{x}$ & $\checkmark$ & $\mathbf{x}$ & $\checkmark$ & 2019 & [13] \\
\hline $\mathbf{x}$ & $x$ & $\mathbf{x}$ & $\checkmark$ & $\mathbf{x}$ & $\mathbf{x}$ & $\checkmark$ & $\begin{array}{c}\text { Complex Network } \\
\text { Theory }\end{array}$ & $\mathbf{x}$ & 2020 & [21] \\
\hline $\mathbf{x}$ & $\mathbf{x}$ & $x$ & $\checkmark$ & $x$ & $x$ & $\checkmark$ & $\mathbf{x}$ & $\checkmark$ & 2009 & [22] \\
\hline$\checkmark$ & $\checkmark$ & $\mathbf{x}$ & $\mathbf{x}$ & $\mathbf{x}$ & $\mathbf{x}$ & $\checkmark$ & $\mathbf{x}$ & $\checkmark$ & 2017 & [14] \\
\hline$\checkmark$ & $\checkmark$ & $\mathbf{x}$ & $\mathbf{x}$ & $\mathbf{x}$ & $\mathbf{x}$ & $\checkmark$ & $\mathbf{x}$ & $\checkmark$ & 2016 & {$[15]$} \\
\hline $\mathbf{x}$ & $\checkmark$ & $x$ & $\checkmark$ & $\checkmark$ & $\checkmark$ & $\checkmark$ & $\mathbf{x}$ & $\checkmark$ & 2019 & [16] \\
\hline$x$ & $\checkmark$ & $\checkmark$ & $\mathbf{x}$ & $x$ & $\mathbf{x}$ & $\checkmark$ & $\mathbf{x}$ & $\checkmark$ & 2020 & [20] \\
\hline$\checkmark$ & $\checkmark$ & $\checkmark$ & $\checkmark$ & $\checkmark$ & $\checkmark$ & $\checkmark$ & $\mathbf{x}$ & $\checkmark$ & \multicolumn{2}{|c|}{ Proposed Method } \\
\hline
\end{tabular}

\section{CPMG's Architecture}

In Figure 1, the architecture of the understudy CPMGs, including cyber and physical subsystems, is shown $[16,20]$. The subsystems of CPMGs could be categorized into two separate general networks: physical and cyber networks, as shown in Figure 1b. Moreover, the cyber network could be divided into different layers, e.g., interface, communication, and decision layers. The different layers of the CPMGs have been depicted in Figure 1c.

The CPMGs' physical/power network consists of renewable and nonrenewable generation units such as WT, PV, microturbine (MT), energy storage system (ESS), power bus, converters, loads, etc. $[23,24]$. The cyber part consists of data collectors, microgrid control centers (MGCCs), controllers, data transitions, status sensors, determination devices, etc.

In this paper, the central control mode of the CPMG has been considered. MGCC makes dissension for the MG's stability in the centralized control mode by collecting data from control devices. Accordingly, the MGCC is the most important subsystem of the CPMG, and its eventual failures might affect the CPMG dramatically. The centralized control system of the CPMG includes the MGCC and control units of sources and loads (microunit control (MC) and load control (LC)). 


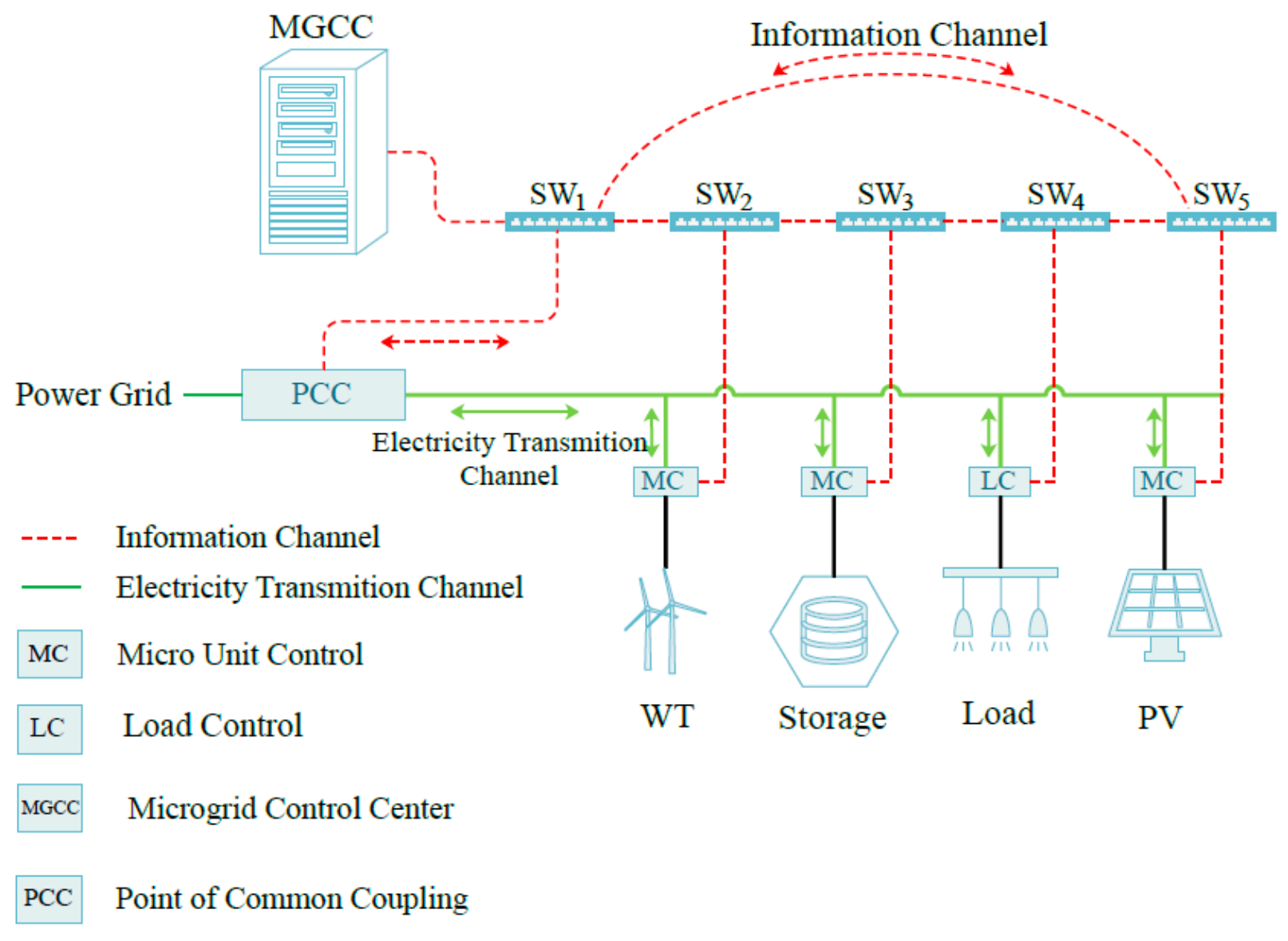

(a)

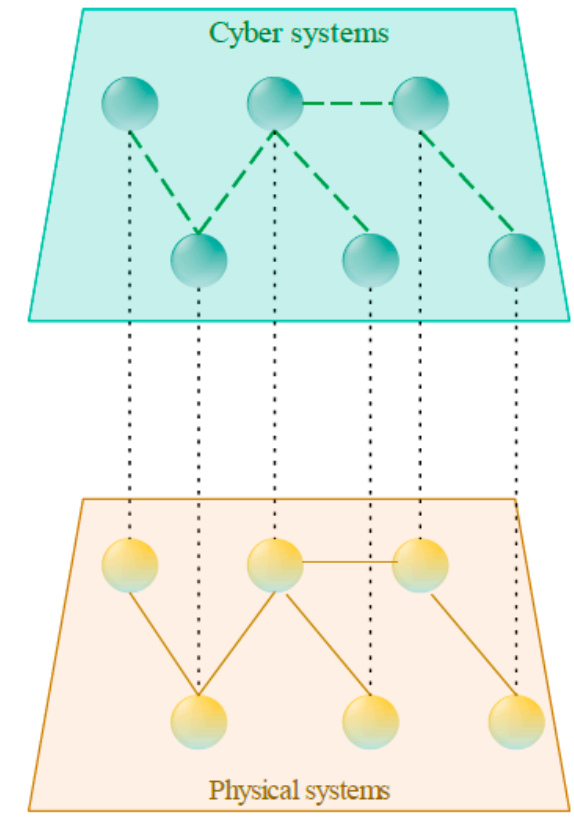

(b)

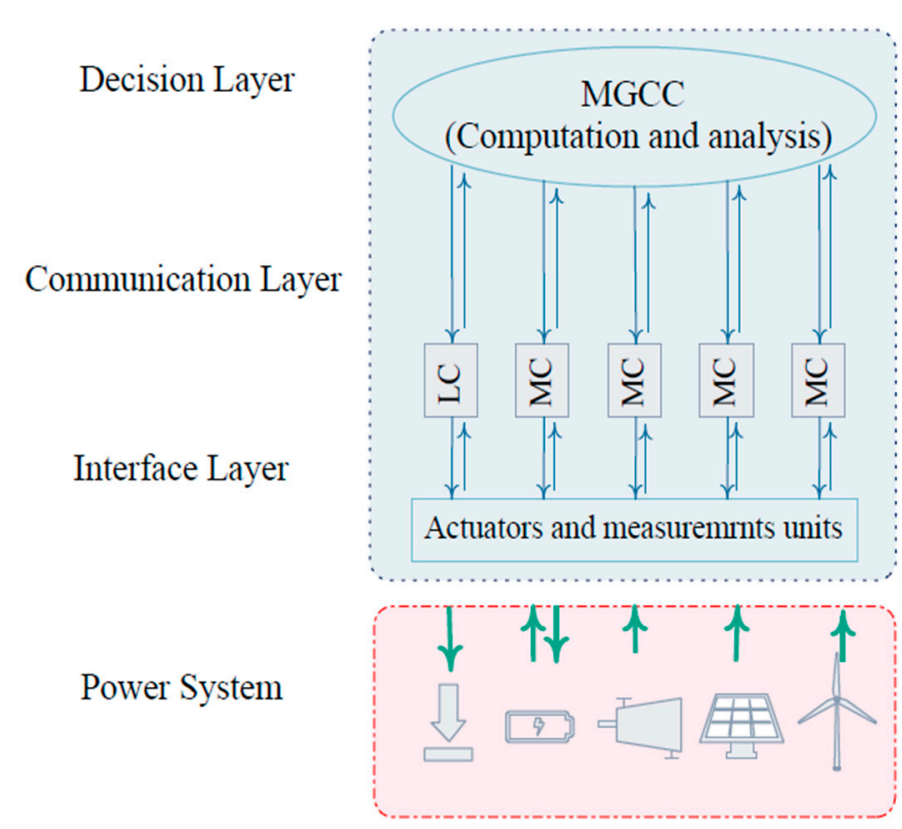

(c)

Figure 1. Architecture of the understudy CPMGs; (a) bidirectional information/power channels; (b) cyber-physical nature; (c) different layers and interfaces $[16,20]$. 
The MGCC must control the power balance between the supply side and demand side at each moment. In addition, the MGCC is in charge of frequency and voltage stability. The MCs and LCs are responsible for collecting DGs and loads information such as output power, voltage, and frequency, and sending these data to the MGCC. The complete MG control process could be described as follows [16]:

1. The gathering of DGs and loads information by the MCs and LCs, respectively;

2. Transmitting the information through the information channel connecting the MGCC, MCs, and LCs;

3. Checking of the power balance condition and other operation aspects by the MGCC;

4. Adopting orders based on information received, such as increasing power generation or decreasing power in the supply side, and load management strategies on the demand side;

5. Transmitting the commands generated by the MGCC using the information channel between the MGCC, MCs, and LCs; and

6. Executing the MGCCs' generated commands by local controllers.

In CPMGs, in addition to physical failures and interruptions, the cyber system might affect the system's reliability [25]. In this paper, the following cyber-power interdependencies are considered:

- $\quad$ Failure of the cyber system's elements: The appropriate and stable operation of CPMGs requires available power and information channels. The failures in cyber layers, e.g., in the MGCC, MCs, and LCs result in energy not being supplied, similar to failures in power elements $[26,27]$.

- Information transmission faults: It is essential to receive the correct information from the sensors and control units for the MGCC to make correct decisions [28]. Hence, the information transmission faults might lead to incorrect decisions. Consequently, the appropriate operation of the CPMG and its stability might be threatened.

- Routing faults: The CPMG equipment's real-time operation needs to receive the correct information package. Therefore, routing faults in the sending or receiving of the information package might affect the instantaneous function of the control and cyber systems [29]. Hence, the CPMG is influenced by routing faults.

- Delay in data transfer: The fast performance of cyber elements and information channels is crucial to meet power balance conditions in CPMGs. Therefore, a delay in data transfer could cause a lack of timely communication between the control units, resulting in a loss of power balance [30].

In Table 2, the uncertainties in both cyber and power networks of CPMGs have been listed. Comprehensive consideration of all cyber and power uncertainties is one of the major contributions of this research.

As seen in Table 2, physical/power and cyber subsystem failures are major sources of a CPMG's uncertainties. The time to failures (TTF) and time to repairs (TTR) of a CPMG's subsystems are stochastic parameters, and their probabilistic behaviors should be concerned in reliability evaluations [31].

Environmental parameters, e.g., wind speed and solar irradiance, influence renewable DGs' output power. Hence, the uncertainties of environmental parameters should be considered in the physical/power network.

Moreover, the uncertainties and faults of information transmission delay and information transmission faults (payload errors and hear errors) are concerned in this article. The probability distributions of discussed stochastic parameters have also been presented in Table 2. 
Table 2. Uncertainties of the CPMGs.

\begin{tabular}{|c|c|c|c|c|}
\hline CPMG Layers & Sub-System & Stochastic Parameter & Uncertainties' Source & Probability Distribution \\
\hline \multirow{8}{*}{ Physical network } & \multirow[b]{2}{*}{ WT } & WT output power & Wind speed variability & Weibull [15] \\
\hline & & $\begin{array}{l}\text { TTF } \\
\text { TTR }\end{array}$ & Random failure & Exponential [16] \\
\hline & \multirow{2}{*}{ PV } & PV output power & $\begin{array}{l}\text { Solar irradiation } \\
\text { variability }\end{array}$ & Beta [15] \\
\hline & & $\begin{array}{l}\text { TTF } \\
\text { TTR }\end{array}$ & Random failure & Exponential [13] \\
\hline & MT & $\begin{array}{l}\text { TTF } \\
\text { TTR }\end{array}$ & Random failure & Exponential [16] \\
\hline & Bus & $\begin{array}{l}\text { TTF } \\
\text { TTR }\end{array}$ & Random failure & Exponential [16] \\
\hline & ESS & $\begin{array}{l}\text { TTF } \\
\text { TTR }\end{array}$ & Random failure & Exponential [16] \\
\hline & Demand-side & Load value & $\begin{array}{l}\text { Consumption } \\
\text { variability }\end{array}$ & Normal [32] \\
\hline \multirow{7}{*}{ Cyber network } & MGCC & $\begin{array}{l}\text { TTF } \\
\text { TTR }\end{array}$ & Random failure & Exponential [13] \\
\hline & $\begin{array}{l}\text { Information } \\
\text { channel }\end{array}$ & $\begin{array}{l}\text { TTF } \\
\text { TTR }\end{array}$ & Random failure & Exponential [16] \\
\hline & Switch & $\begin{array}{l}\text { TTF } \\
\text { TTR }\end{array}$ & Random failure & Exponential [16] \\
\hline & $\begin{array}{l}\text { Information } \\
\text { terminal }\end{array}$ & $\begin{array}{l}\text { TTF } \\
\text { TTR }\end{array}$ & Random failure & Exponential [16] \\
\hline & $\begin{array}{c}\text { Information } \\
\text { transmission delay }\end{array}$ & $\begin{array}{l}\text { Delay time in } \\
\text { information } \\
\text { transmission proses }\end{array}$ & Random amount & Exponential $[33,34]$ \\
\hline & \multirow{2}{*}{$\begin{array}{l}\text { Information } \\
\text { transmission }\end{array}$} & Payload error & Random fault & $\begin{array}{c}\text { Gaussian white noise } \\
\text { (GWN) }[35,36]\end{array}$ \\
\hline & & Header error & Random fault & GWN $[35,36]$ \\
\hline
\end{tabular}

\section{Modeling of the Proposed Reliability Evaluation of CPMGs}

\subsection{Cyber-Physical Interdependencies Due to Cyber Failures}

The state of the CPMG should be determined to evaluate the system's reliability, such as in $[17,37]$. The CPMG's state, including both cyber and power elements, could be modeled using the following equation:

$$
\begin{gathered}
M S_{i}=\left[M E_{1}(t), \ldots, M E_{j}(t), \ldots, M E_{N_{P}+N_{C}}(t)\right]=\left[\begin{array}{c}
M E_{1}(t), \ldots, M E_{k}(t), \ldots, M E_{N_{P}}(t), \\
\ldots, M E_{N_{P}+l}(t), \ldots, M E_{N_{P}+N_{C}}(t)
\end{array}\right] \\
i=1: N_{M S}, j=1: N_{P}+N_{C}, k=1: N_{P}, l=1: N_{C}
\end{gathered}
$$

where the CPMG's state at each time step $\left(M S_{i}(t)\right)$ is distinguished based on the state of its physical elements $M E_{k}(t)$ and cyber elements $M S_{l}(t)$. The two-state reliability model is one of the most common models for modeling the CPMGs, as depicted in Figure 2 [38]. The binary variables represent the CPMG elements' states. The zero value of each element state represents that the corresponding element is unavailable. Otherwise, the discussed element is in service [39]. The availability state of any subsystem could be represented using the time to failure (TTF) and time to repair (TTR), as shown in Figure 3 [40,41]. In this paper, the two-state reliability model has been used for both the cyber and physical networks' elements. Hence, the failures in cyber and physical networks could be determined using the two-state reliability model. In Figure $2, \lambda$ and $\mu$ denote the failure rate and repair rate, respectively. It means that the system is transited from the Up sate to the Down state based on the failure rate $(\lambda)$ and similarly the system transition from the Down state to the Up state occurs according to the repair rate $(\mu)$. 


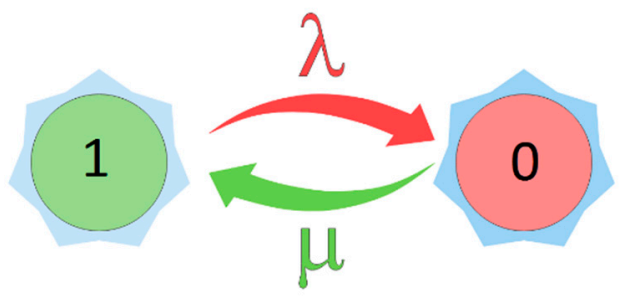

Figure 2. Two-state reliability model for CPMG's elements [16].

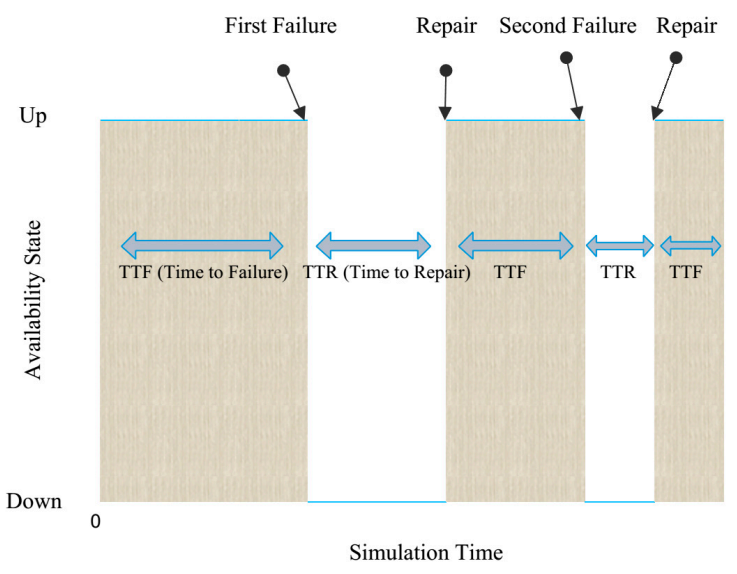

Figure 3. State of CPMG's elements based on the two-state reliability model [42].

In this paper, the exponential distribution has been used to simulate the Up and Down states [43]. The availability and unavailability probabilities have been mathematically expressed in (2) and (3).

$$
\begin{aligned}
& A_{j}(t)=1-\exp \left[\lambda_{j} \times t\right] j=1: N_{P}+N_{C} \\
& U_{j}(t)=1-\exp \left[\mu_{j} \times t\right] j=1: N_{P}+N_{C}
\end{aligned}
$$

To simulate the stochastic time-series of CPMG elements' availability $\left(\left.M S_{i}(t)\right|_{t=1: 8760 \times T}\right)$, the TTFs and TTRs should be generated using the MCS, as shown in (4) and (5). As seen, the mean time to failure (MTTF), mean time to repair (MTTR), and random variables uniformly distributed in $\left(\begin{array}{ll}0 & 1\end{array}\right)$ are utilized to generate the TTF and TTR.

$$
\begin{aligned}
\operatorname{TTF}_{j} & =\mathrm{MTTF}_{j} \times \ln (x) \\
\operatorname{TTR}_{j} & =\mathrm{MTTR}_{j} \times \ln (x)
\end{aligned}
$$

The cyber-physical interdependencies matrix (CPIM) at each time step could be defined using (6). As shown, the CPIM consists of power interconnections, cyber interconnections, and cyber-power interdependencies. In this paper, this matrix is used to create the graph of the CPMG. 


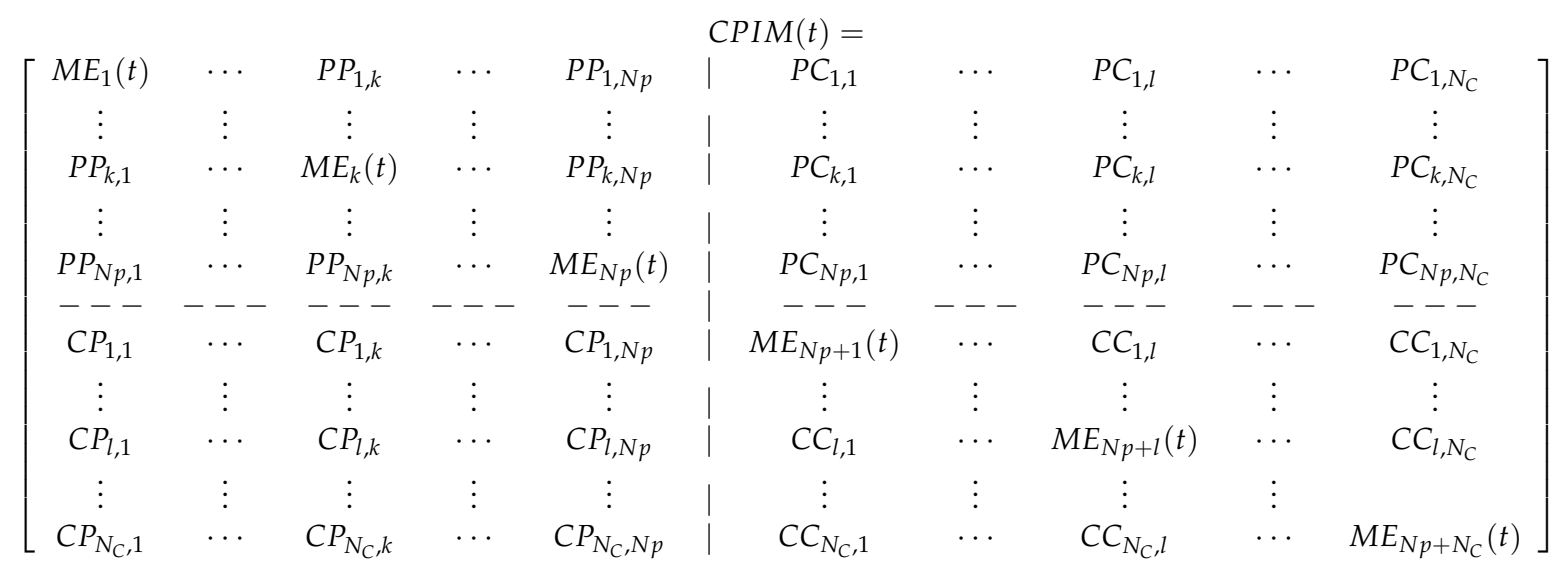

Mapping the cyber failures to the physical/power network is essential for the reliability assessment of CPMGs. Hence, in the proposed method, the cyber-physical interdependencies are first concerned with mapping the unavailability of interconnected cyber elements to the physical layer by (7). If there are some cyber-power links between cyber elements and a physical element, all interconnected cyber elements' appropriate performance and availability are necessary. The physical element state should be changed due to any failure in interconnected cyber elements.

Afterward, the CPIM should be updated due to failures in power and cyber elements because the system graph and its interconnections are affected by these failures. In (8), updating the interconnections of the CPMGs is shown.

$$
\begin{gathered}
C P I M(t) \rightarrow C P I M^{\prime}(t): M E_{\chi}^{\prime}(t)=M E_{\chi}(t) \times \prod_{l=N_{P}+1}^{N_{P}+N_{C}}\left(M E_{l}(t) \mid\right. \\
C P I C M^{\prime}(t) \rightarrow C P I M^{\prime \prime}(t): \begin{cases}P P_{k, \chi}^{\prime \prime}=M E_{k}^{\prime}(t) \times P P_{k, \beta}^{\prime} & k=1: N_{P}, \chi=1: N_{P} \\
P P_{\chi, k}^{\prime \prime}=M E_{k}^{\prime}(t) \times P P_{\chi, k}^{\prime} & k=1: N_{P}, \chi=1: N_{P} \\
P C_{k, \xi}^{\prime \prime}=M E_{k}^{\prime}(t) \times P C_{k, \xi}^{\prime} & k=1: N_{P}, \xi=1: N_{C} \\
C C_{l, \xi}^{\prime \prime}=M E_{l}^{\prime}(t) \times C C_{l, \xi}^{\prime \prime} & l=1: N_{C}, \xi=1: N_{C} \\
C C_{\xi, l}^{\prime \prime}=M E_{l}^{\prime}(t) \times C C_{\xi, l}^{\prime \prime} & l=1: N_{C}, \xi=1: N_{C} \\
C P_{l, \chi}^{\prime \prime}=M E_{l}^{\prime}(t) \times C P_{l, \chi}^{\prime} & k=1: N_{P}, l=1: N_{C}\end{cases}
\end{gathered}
$$

Finally, the power channels and information channels should be determined using (9)-(11). The shortest path function (SPF) based on theory graph concepts has been utilized to distinguish power and information channels. If there is a path between the power sending terminal (PST) and the power receiving terminal (PRT), the summation of the shortest path would not be zero, and it means that there is a power channel $(P c h)$, as shown in (10). Otherwise, the power channel index would be assigned to zero, and no power channel exists between discussed terminals. Similarly, the state of the information channel (Ich) between the cyber sending terminal (CST) and the cyber receiving terminal (CRT) is determined using (11).

$$
\begin{gathered}
\text { Graph }(t)=\operatorname{graph}(\operatorname{CPIM}(t)) \\
\operatorname{Pch}\left(P S T_{q}, P R T_{r}, t\right)= \begin{cases}1 & \operatorname{If} \sum \operatorname{SPF}\left(\operatorname{Graph}(t), P S T_{q}, P R T_{r}\right) \geq 1 \\
0 & \operatorname{If} \sum \operatorname{SPF}\left(\operatorname{Graph}(t), P S T_{q}, P R T_{r}\right)=0\end{cases} \\
\operatorname{Ich}\left(\operatorname{CST}_{y}, C R T_{z}, t\right)= \begin{cases}1 & \operatorname{If} \sum \operatorname{SPF}\left(\operatorname{Graph}(t), C S T_{y}, C R T_{z}\right) \geq 1 \\
0 & \operatorname{If} \sum \operatorname{SPF}\left(\operatorname{Graph}(t), C S T_{y}, C R T_{z}\right)=0\end{cases}
\end{gathered}
$$




\subsection{Information Transmission Errors and Delays}

To assess the reliability of CPMGs, it is essential to concern the routing errors, data transmission delays, and dynamic transmission errors, as shown in Figure 4.

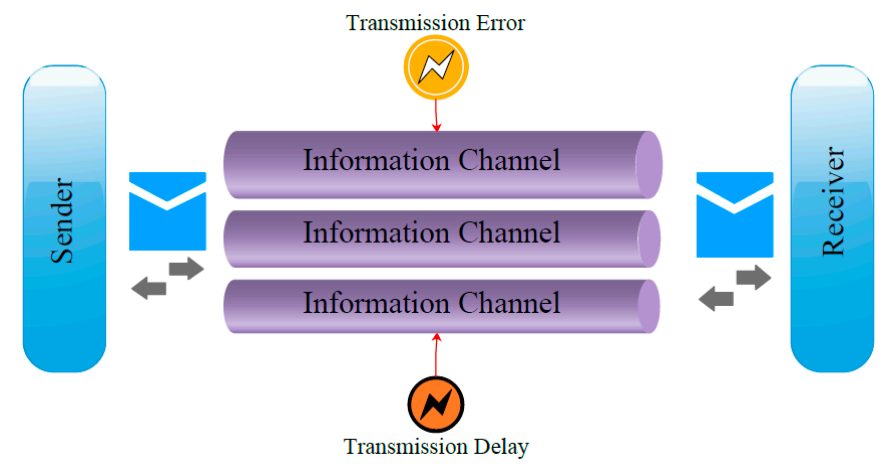

Figure 4. Conceptual structure of information transmission, including transmission errors and time delays.

The ideal information channel could be presented using (12).

$$
P A C_{\text {Receive }}\left[P A C_{\text {Received }}^{f}(t), D E S_{\text {Received }}^{f}\right]=P A C_{\text {sent }}\left[P A C_{\text {Sent }}^{f}(t), D E S_{\text {Sent }}^{f}\right] f=1: N_{\text {Ich }}
$$

The transmission with delay in an information channel should be simulated according to (13). The delay might affect the information transmission if it exceeds the maximum allowed delay margin.

$$
P A C_{\text {Receive }}\left[P A C_{\text {Received }}^{f}(t), D E S_{\text {Received }}^{f}\right]=P A C_{\text {sent }}\left[P A C_{\text {Sent }}^{f}\left(t+E_{\text {Delay }}^{f}(t)\right), D E S_{\text {Sent }}^{f}\right] f=1: N_{\text {Ich }}
$$

The time delay in information transmission is probabilistic. The exponential probability distribution is one of the most well-known distributions, and has been used for simulating the statistical behaviors of time delays. The time delay at each time step could be simulated using the MCS based on (14). As demonstrated in (14), a random variable uniformly distributed in $\left(\begin{array}{ll}0 & 1)\end{array}\right)$ is generated, and the mean value of time delays based on measured actual historical data is used to simulate the stochastic time delays by exponential probability distribution.

$$
E_{\text {Delay }}^{f}(t) \equiv \bar{E}_{\text {Delay }}^{f} \times \ln (x)
$$

The data packet from the LC/MC to the MGCC, such as other data packets in other applications, consists of payload and header [44,45]. The first part of the data packet (payload) contains commands and information that must be transmitted, such as current, voltage, frequency, and so on. The second part (header) contains the destination address. For instance, in a typical data packet $\left(P A C_{\text {sent }}\left[P A C_{\text {send }}^{f}(t), D E S_{\text {sent }}^{f}\right]\right)$, the transmission destination and the data contents are represented by $P A C_{\text {send }}^{f}(t)$ and $D E S_{\text {sent }}^{f}$, respectively.

The information transmission without any errors in payloads and headers of information channels is shown in (13). However, the errors in payloads $\left(E_{\text {Payload }}^{f}(t)\right)$ and headers $\left(E_{\text {Header }}^{f}(t)\right)$ should be addressed to precisely calculate the reliability of CPMGs. The Gaussian distribution of white noise has been reported to study the statistical behaviors of payload and header errors in transmission information. The information transmission considering time delay, payload errors, and header errors should be simulated by the MCS. The white noise and a random variable uniformly distributed in $\left(\begin{array}{ll}0 & 1\end{array}\right)$ should be generated to simulate the payload and header errors, as mathematically expressed in (15) and (16) [16].

$$
P A C_{\text {Received }}^{f}(t)=I_{\text {ch }} \times\left(P A C_{\text {Sent }}^{f}\left(t+E_{\text {Delay }}^{f}(t)\right)-\operatorname{Int}\left[u-\operatorname{Pr}_{E_{\text {Payload }}^{f}}\right] \times\left(E_{\text {Payload }}^{f}(t)\right)\right)
$$




$$
D E S_{\text {Received }}^{f}=D E S_{\text {sent }}^{f}-\operatorname{Int}\left[u-\operatorname{Pr}_{E_{\text {Header }}^{f}}\right] \times\left(E_{\text {Header }}^{f}(t)\right)
$$

\subsection{Stochastic Simulation of Renewable-Based DGs}

The wind speed and technical characteristics influence the output energy of WTs. Since the wind speed is an uncertain environmental parameter, its stochastic behavior should be simulated using the MCS. The Weibull distribution has been selected in this paper to model the statistical behaviors of wind speed, which is one of the most common distributions for simulating the wind speed's stochastic nature [46]. As expressed in (17), the wind speed is simulated by the Weibull cumulative density function (CDF) inverse and a random variable in the proposed MCS-based method. Moreover, the WT output power is computed by (18).

$$
\begin{gathered}
v=F^{-1}(x \mid c, k)=-c \cdot \ln (1-x)^{\frac{1}{k}}=-c \cdot \ln (x)^{\frac{1}{k}} \\
P_{W T}(v(t), t)=\left\{\begin{array}{lc}
0 & 0 \leq v(t)<v_{c i} \\
P_{\text {Rated }} \times \frac{\left(v(t)-V_{c i}\right)}{\left(V_{\text {rated }}-V_{c i}\right)} & v_{c i} \leq v(t)<v_{\text {rated }} \\
P_{\text {Rated }} & v_{\text {rated }} \leq v(t) \leq v_{c o} \\
0 & v_{c o}<v(t)
\end{array}\right.
\end{gathered}
$$

The output power of $P V$ units depends on the amount of solar radiation and the solar clearness index $(S C I)$. Since the distribution of SCI mainly follows the Beta probability distribution $[47,48]$, the MCS simulates the SCI by the Beta CDF inverse based on historical data. The Beta PDF and simulating the SCI using the MCS have been presented in (19) and (20) [42].

$$
\begin{gathered}
f(S C I \mid \alpha, \beta)=\frac{\Gamma(\alpha+\beta)}{\Gamma(\alpha) \times \Gamma(\beta)} \times S C I^{\alpha-1} \times(1-S C I)^{\beta-1} \\
S C I=F^{-1}(u \mid \alpha, \beta)
\end{gathered}
$$

Finally, the output power of $P V$ units should be distinguished using (21)-(24) based on environmental parameters and technical characteristics $[48,49]$.

$$
\begin{gathered}
T_{c}(t)=T_{a}(t)+\left(G(t) \times \frac{\left(N_{O T}-20\right)}{800}\right) \\
I(t)=S C I(t) \times\left(I_{S C}+\left(T_{\mathcal{c}}(t)-T_{a}(t)\right) \times K_{I}\right) \\
V(t)=V_{o c}-K_{V} \times T_{\mathcal{c}}(t) \\
P_{P V}(t)=N_{P V} \times I(t) \times V(t) \times \eta
\end{gathered}
$$

\subsection{Stochastic Simulation of Loads}

In this paper, the uncertainties of loads have been concerned. The normal probability distribution is one of the most common probability distributions to model the uncertainties of load values. The probabilistic load values are simulated using the normal CDF inverse by the MCS. Modeling the uncertainties of the CPMG's load is one of this study's contributions, which has not received a great deal of attention in current studies.

\subsection{Reliability Calculations}

The power balance condition should be met as depicted in (25). The adequacy assessment should be performed to check the values of the supply side, demand side, and their 
difference according to (26). Consequently, the load curtailment and at-risk state at each time step could be distinguished by (27) and (28) [50].

$$
\begin{gathered}
\sum_{g=1}^{N_{D G}} P_{g}(t) \geq P_{\text {Loads }}(t)+P_{\text {Loss }}(t) \\
\Delta L G(t)=P_{\text {Loads }}(t)+P_{\text {Loss }}(t)-\sum_{g=1}^{N_{D G}} P_{g}(t) \\
L C(t)=\operatorname{Max}\{0, \Delta L G(t)\} \\
A t-\operatorname{risk}(t)= \begin{cases}0 & \text { If } \Delta L G(t) \leq 0 \\
1 & \text { If } \Delta L G(t)>0\end{cases}
\end{gathered}
$$

The reliability indices are determined using the load curtailment of all time steps, according to (29)-(31).

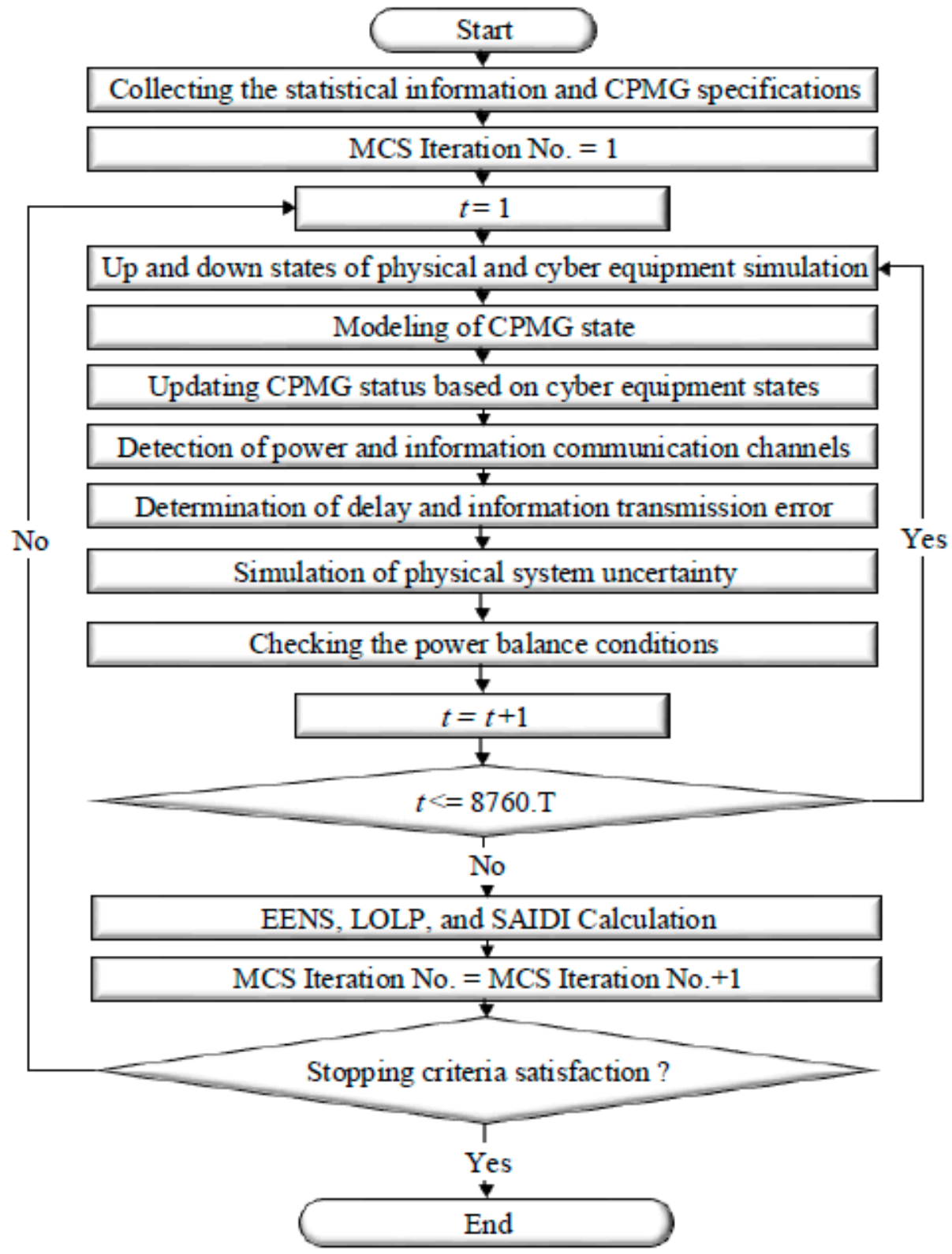

Figure 5. Flowchart of the proposed reliability assessment of CPMGs considering cyber impacts. 


$$
\begin{aligned}
& \text { LOLP }=\frac{\sum_{t=1}^{8760 \times T} A t-\operatorname{risk}(t)}{8760 \times T} \\
& E E N S= \sum_{t=1}^{8760 \times T}(T \times L C(t)) \\
& \text { SAIDI }=\frac{\sum_{t=1}^{8760 \times T}(T \times L C(t))}{\bar{P}_{\text {Load }}}
\end{aligned}
$$

The flowchart of the proposed reliability assessment of CPMGs considering cyberphysical interdependencies, cyber failures, routing errors, time delays in information transmission, and other physical uncertainties, such as the uncertainties of renewable power output, is shown in Figure 5. In this paper, satisfying the number of MCS iterations and the accuracy level have been defined for the stopping criteria of the proposed MCSbased reliability evaluation method.

\section{Test Results and Discussions}

In this paper, the physical structure of the understudy CPMG is shown in Figure 6 [16].

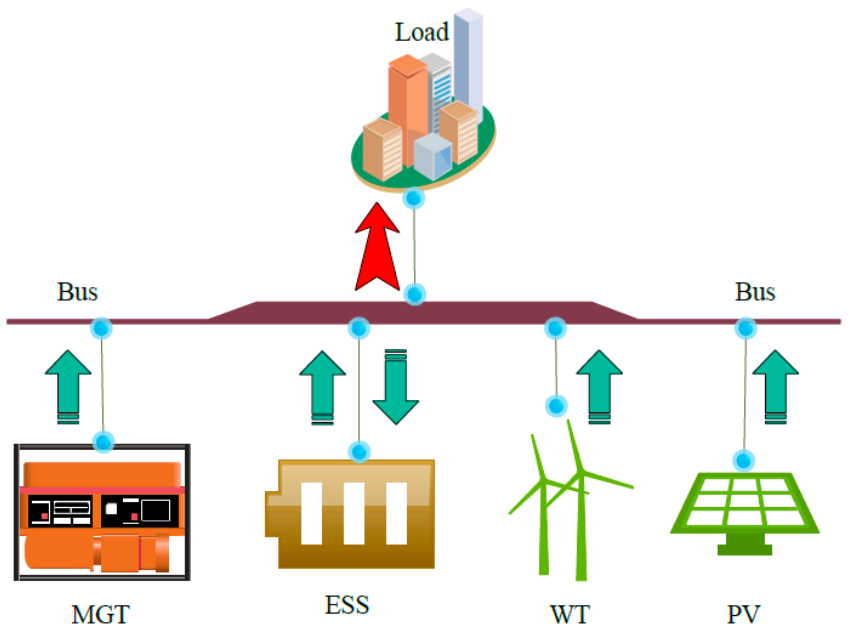

Figure 6. Understudy CPMG [16].

The selected CPMG has been equipped with a $500 \mathrm{kWh}$ ESS. The maximum charging and discharging rate of the ESS have been assumed to be $10 \mathrm{~kW}$. The MGT's maximum and minimum allowed output power and operating range are $100 \mathrm{~kW}$ and $10 \mathrm{~kW}$, respectively.

The stochastic behaviors of load value at each time step have been simulated based on $15 \mathrm{~min}$ load values for three years, measured by the Kashan Electrical Distribution Company. The Sanjesh Afzar Asia (a manufacturer in Tehran, Iran) measurement instruments have been used for collecting the historical data of load values. The historical wind speed and SCI data used in this study are based on actual measurements in a city located in the center of Iran [51]. In Figure 7, typical one-year historical data of load, solar irradiance, and wind speed have been shown. 


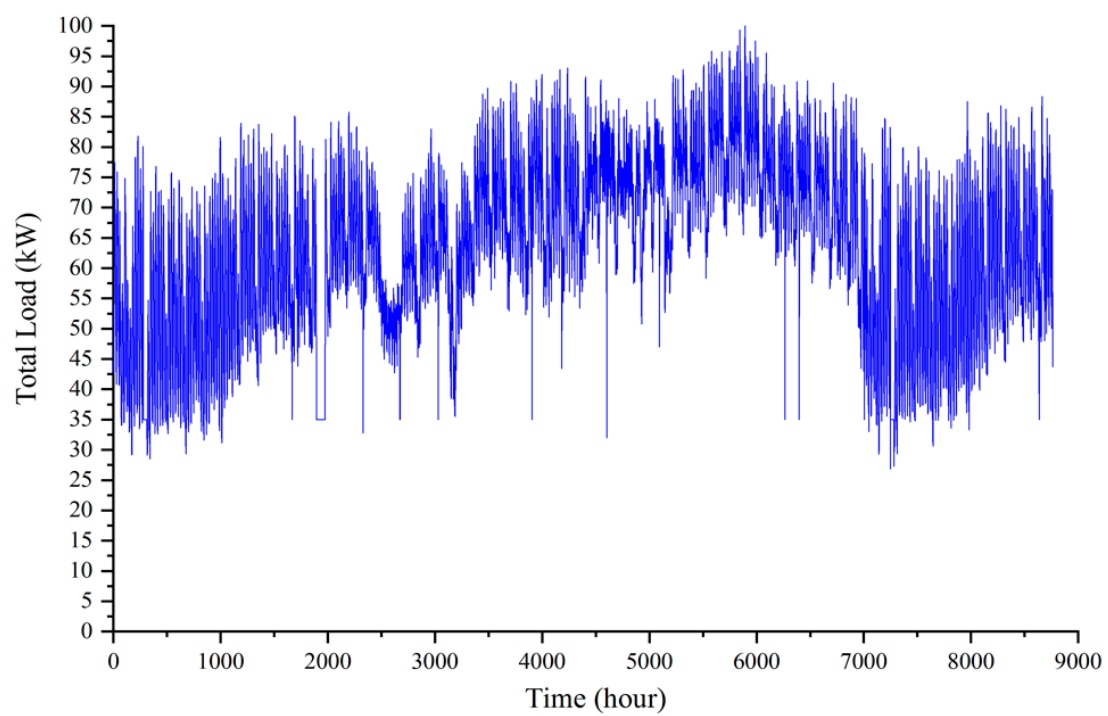

(a) Typical one-year historical load data.

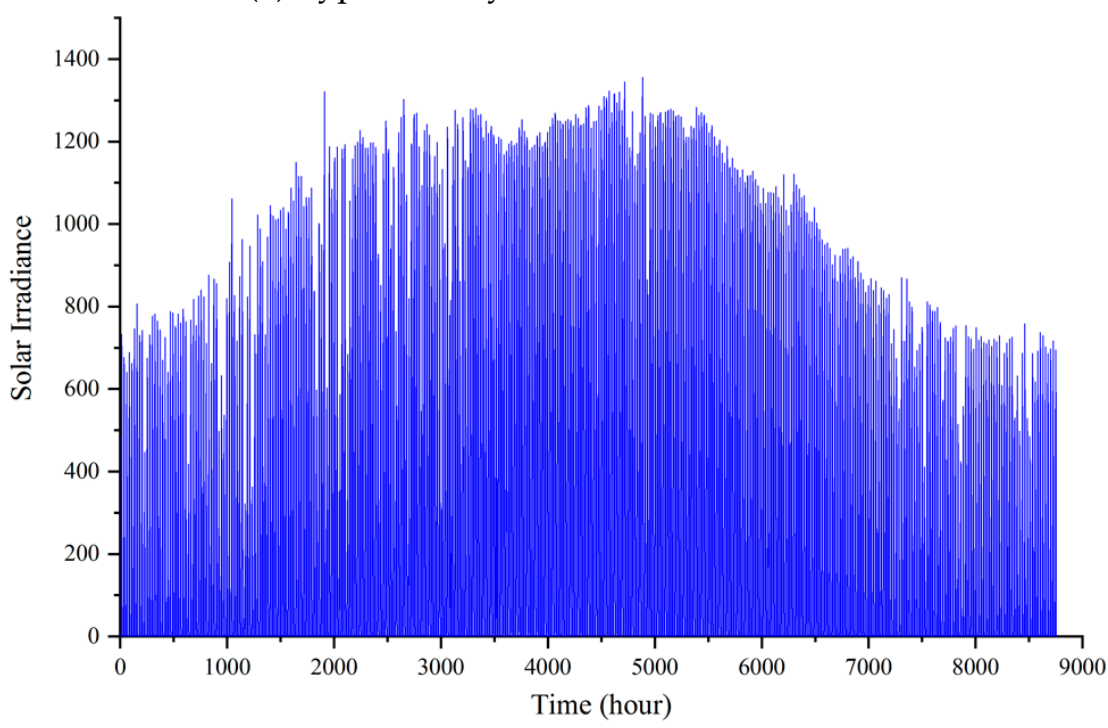

(b) Typical one-year historical solar irradiance data.

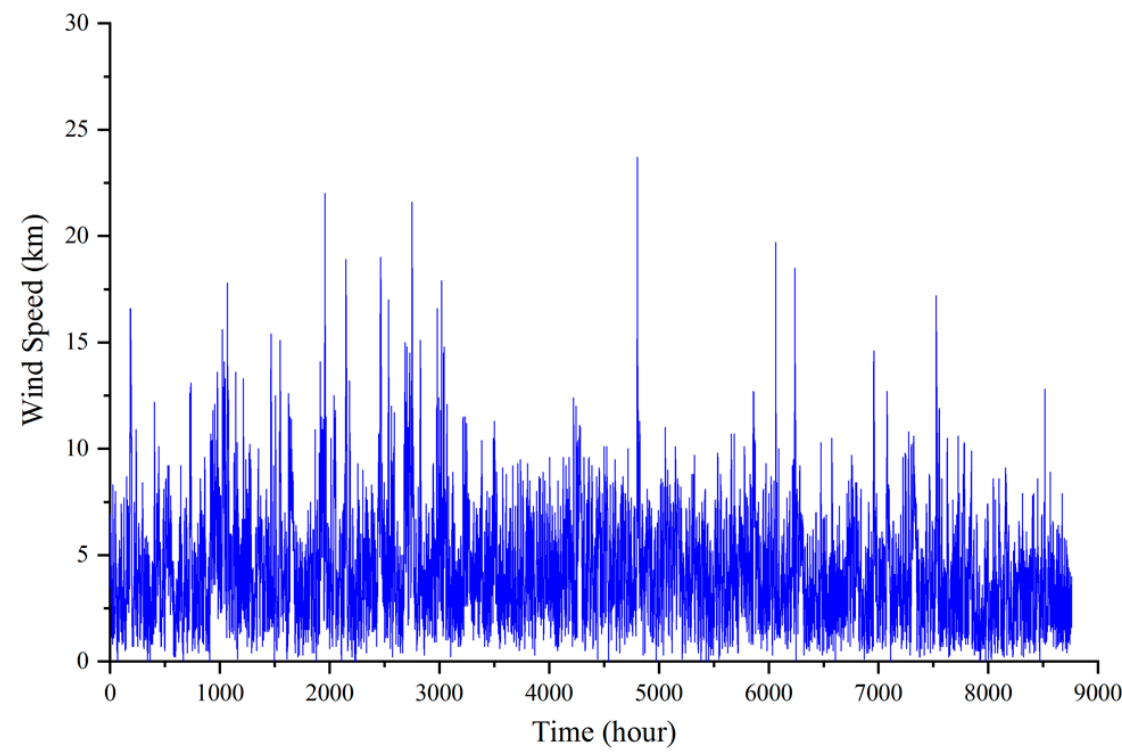

(c) Typical one-year historical wind speed data.

Figure 7. Typical one-year historical data of load, solar irradiance, and wind speed [51]. 
The reliability specifications of the understudy CPMG's elements are given in Table $3[36,52-54]$ and Table $4[13,16,55,56]$. Also, in Table 5, the information transmission errors based on data of [36,52-54] has been demonstrated.

Table 3. Statistical parameters of the historical SCI [51].

\begin{tabular}{ccc}
\hline Time (Hour) & Beta PDF Parameter $(\boldsymbol{\alpha})$ & Beta PDF Parameter $(\boldsymbol{\beta})$ \\
\hline 7 & 0.604 & 9.2272 \\
8 & 1.1985 & 4.8892 \\
9 & 2.1071 & 3.6774 \\
10 & 2.8066 & 2.6887 \\
11 & 3.0563 & 1.8086 \\
12 & 1.611 & 1.0295 \\
13 & 2.8231 & 1.2454 \\
14 & 2.5989 & 1.4137 \\
15 & 2.7887 & 2.2633 \\
16 & 2.4427 & 3.4466 \\
17 & 1.8686 & 5.3861 \\
18 & 0.9021 & 6.7819 \\
\hline
\end{tabular}

Table 4. CPMG's cyber and power elements $[13,16,55,56]$.

\begin{tabular}{ccc}
\hline Element & Repair Time (h) & Failure Rate (Failure/Year) \\
\hline MGCC & 48 & 0.25 \\
Network switch & 48 & 0.2 \\
Optical fiber & 4 & 0.0175 \\
Information terminal & 24 & 0.658 \\
MGT & 100 & 1.168 \\
PV & 40 & 0.5 \\
WT & 279 & 0.769 \\
ESS & 7.8 & 0.172 \\
\hline
\end{tabular}

Table 5. Information transmission errors data [36,52-54].

\begin{tabular}{cc}
\hline Parameters & Values \\
\hline Probability of the payload error & 0.0001 \\
Payload error deviation & 0.01 \\
Probability of the routing error & 0.0001 \\
Routing error deviation & 0.01 \\
Average information transmission delay & $1 \mathrm{~s}$ \\
Maximum tolerable delay margin of & $6 \mathrm{~s}$ \\
information transmission & \\
\hline
\end{tabular}

The selected test system is studied under the following scenarios:

- Scenario 1 (WT-100): In the first scenario, only a WT with a maximum capacity of $50 \mathrm{~kW}$ is considered as the renewable DG of the CPMG.

- $\quad$ Scenario 2 (PV-100): In the second scenario, only a PV with a maximum capacity of $50 \mathrm{~kW}$ is considered as the renewable DG of the CPMG.

- $\quad$ Scenario 3 (Wt-50/PV-50): In the third scenario, a PV with a maximum capacity of $25 \mathrm{~kW}$ and a WT with a maximum capacity of $25 \mathrm{~kW}$ are considered as the hybrid renewable DGs of the CPMG.

In addition, to evaluate the different cyber network topologies' impacts on CPMG reliability, the four types of cyber network topologies are considered, as depicted in Figure 8. Topologies 1, 2, and 3 have been extracted from [16], and the fourth topology has been suggested to study the impacts of MGCC and its redundancy. 


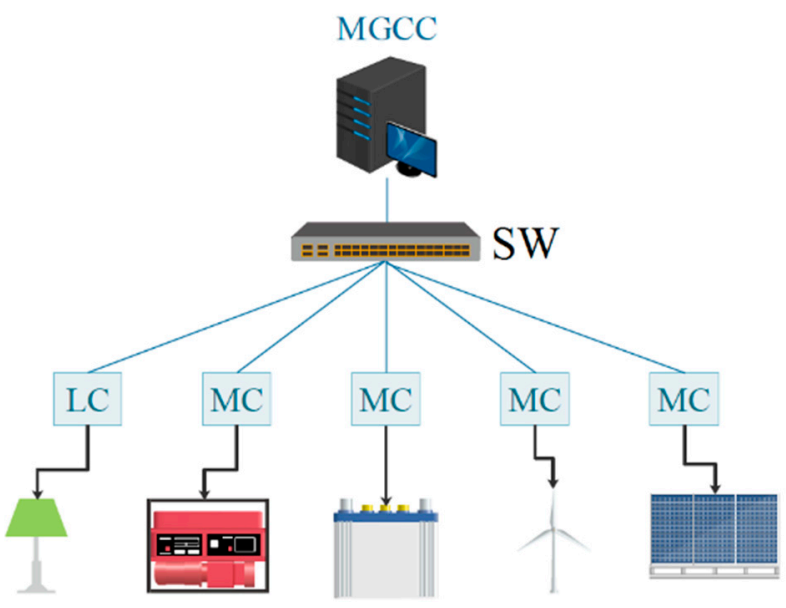

(a) First cyber network topology.

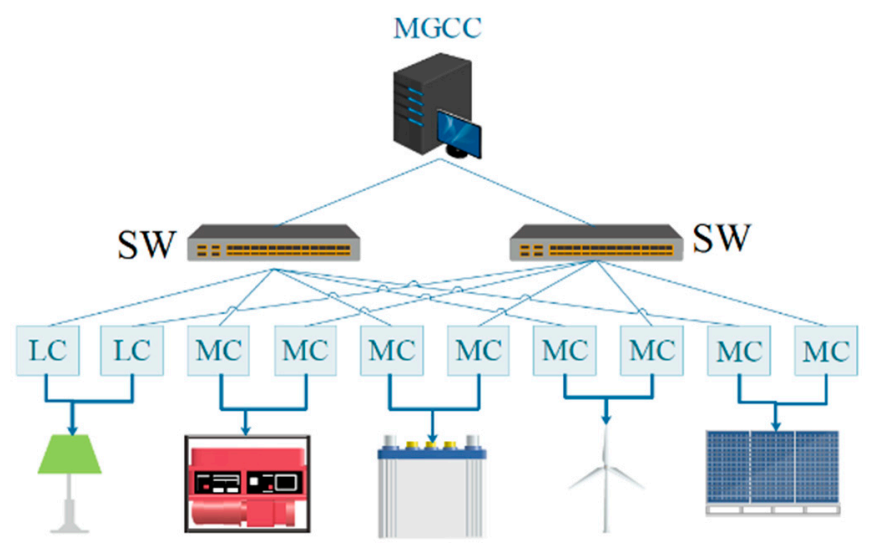

(c) Third cyber network topology.

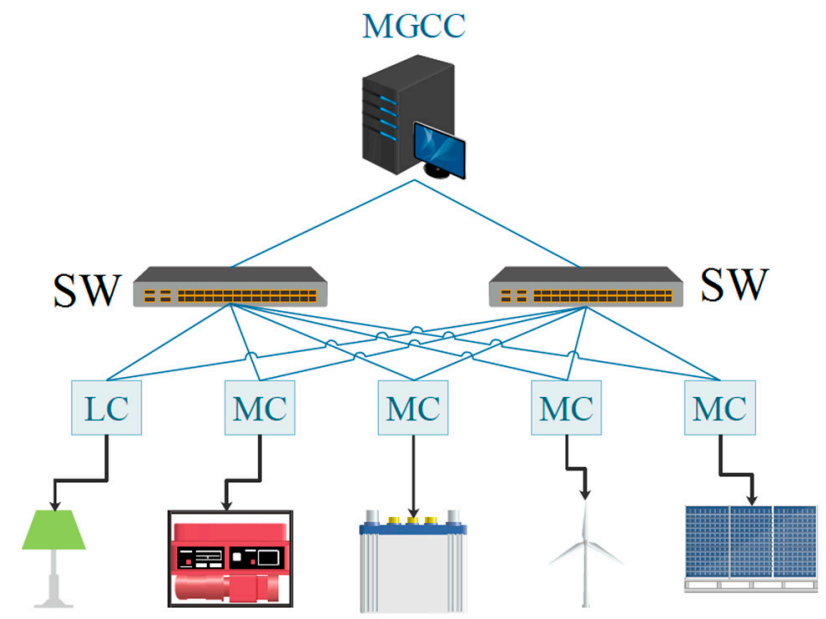

(b) Second cyber network topology.

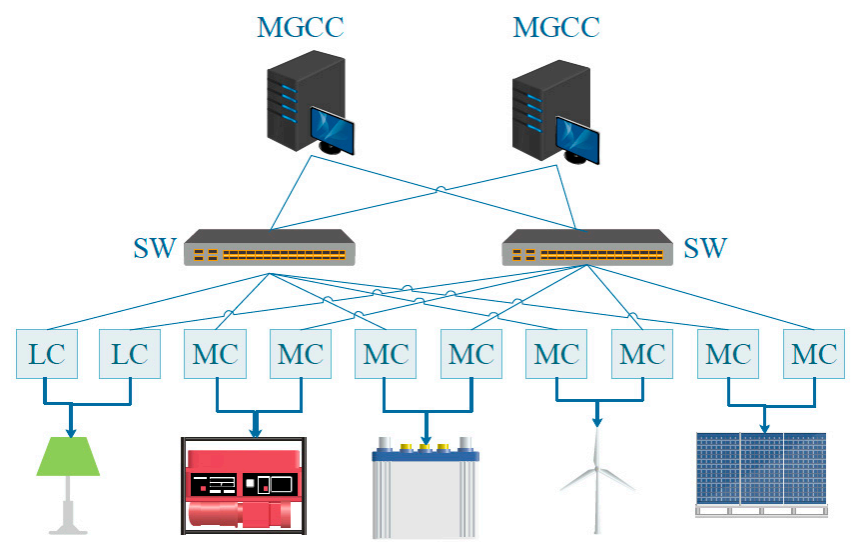

(d) Fourth cyber network topology.

Figure 8. Different cyber network topologies [16].

The first cyber network topology shown in Figure 8 is the base network without any redundancy. In the second topology, the redundancy for the switches and optic fibers has been considered. In the third cyber network topology, in addition to redundant switches and optic fibers, the redundant LCs and MCs have been considered. In current research works such as [16], the redundancy of CPMGs has not been considered, and is studied in the fourth suggested topology.

In the selected test system, the battery is responsible for the initial control, and the MGT is responsible for generating the power shortage in addition to the renewable DGs. The control and operation cycle has been simulated continuously for $1 \mathrm{~min}$ time steps in the proposed MCS-based reliability evaluation method. The iteration numbers of $1000 \mathrm{MCS}$ have been simulated to guarantee the convergence of the simulation-based calculations.

In Table 6, the proposed method's reliability evaluation results under various scenarios and cyber network topologies are presented. The reliability indices without considering the cyber failures and other cyber interruptions are demonstrated.

Moreover, the convergence diagrams of the MCS-based methods under Scenarios 1, 2, and 3 (PV and WT-based and hybrid renewable-based DGs scenarios) are shown in Figures 9-11. As depicted, the expected energy not-supplied (EENS) of the proposed MCS-based method under different cyber network topologies and DG scenarios has been converged completely. 
Table 6. Reliability evaluation results of the proposed method under various scenarios and cyber network topologies.

\begin{tabular}{|c|c|c|c|c|c|c|c|}
\hline \multirow[b]{2}{*}{ Scenario No. } & \multirow{2}{*}{ Topology No. } & \multicolumn{3}{|c|}{ With Cyber Impacts } & \multicolumn{3}{|c|}{ Without Cyber Impacts } \\
\hline & & $\begin{array}{c}\text { EENS } \\
\text { (kWh/Year) }\end{array}$ & LOLP (\%) & $\begin{array}{l}\text { SAIDI } \\
\text { (Hour) }\end{array}$ & $\begin{array}{c}\text { EENS } \\
(\mathrm{kWh} / \text { Year) }\end{array}$ & LOLP (\%) & $\begin{array}{l}\text { SAIDI } \\
\text { (Hour) }\end{array}$ \\
\hline \multirow{4}{*}{$\begin{array}{l}\text { Scenario } 1 \\
\text { (WT-100) }\end{array}$} & 1 & 6004.5 & 1.6481 & 89.71 & \multirow{4}{*}{3868.5} & \multirow{4}{*}{1.1215} & \multirow{4}{*}{55.726} \\
\hline & 2 & 4796.4 & 1.4142 & 73.571 & & & \\
\hline & 3 & 4627.4 & 1.2761 & 68.616 & & & \\
\hline & 4 & 3929.5 & 1.151 & 57.656 & & & \\
\hline \multirow{4}{*}{$\begin{array}{c}\text { Scenario } 2 \\
(\mathrm{PV}-100)\end{array}$} & 1 & 7368 & 1.7468 & 110.1 & \multirow{4}{*}{4871.7} & \multirow{4}{*}{1.1986} & \multirow{4}{*}{71.165} \\
\hline & 2 & 6152.2 & 1.5307 & 94.281 & & & \\
\hline & 3 & 5631.7 & 1.3525 & 83.59 & & & \\
\hline & 4 & 4933.8 & 1.2274 & 72.63 & & & \\
\hline \multirow{4}{*}{$\begin{array}{c}\text { Scenario } 3 \\
(\text { WT-50/PV-50) }\end{array}$} & 1 & 6199.7 & 1.7771 & 95.523 & \multirow{4}{*}{4125.1} & \multirow{4}{*}{1.2478} & \multirow{4}{*}{61.68} \\
\hline & 2 & 5425.5 & 1.5854 & 81.748 & & & \\
\hline & 3 & 4917.7 & 1.4148 & 74.266 & & & \\
\hline & 4 & 4175.5 & 1.2829 & 62.704 & & & \\
\hline
\end{tabular}

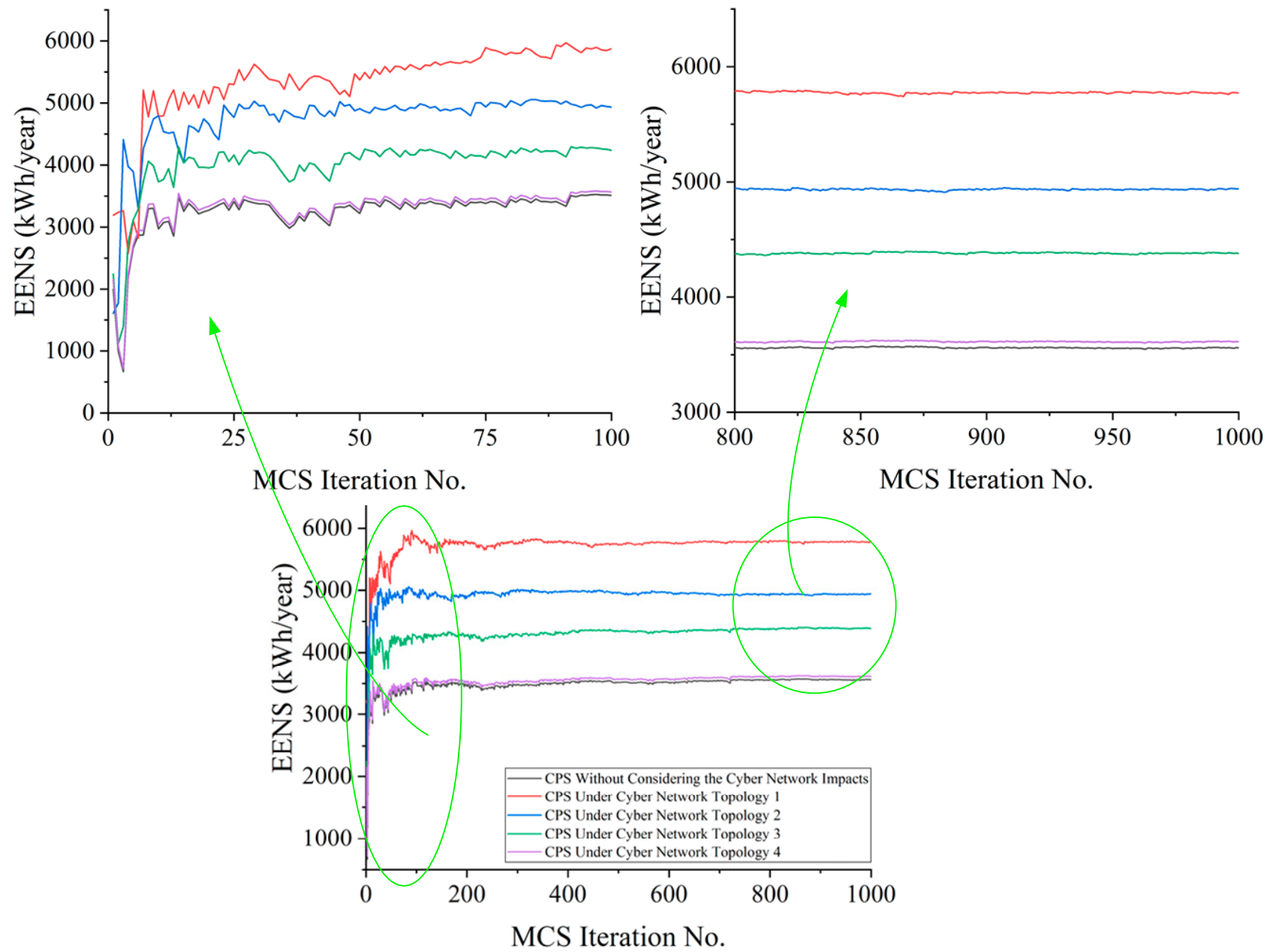

Figure 9. Convergence diagram of the MCS-based reliability evaluation of the CPMG under Scenario 1 and different cyber network topologies. 


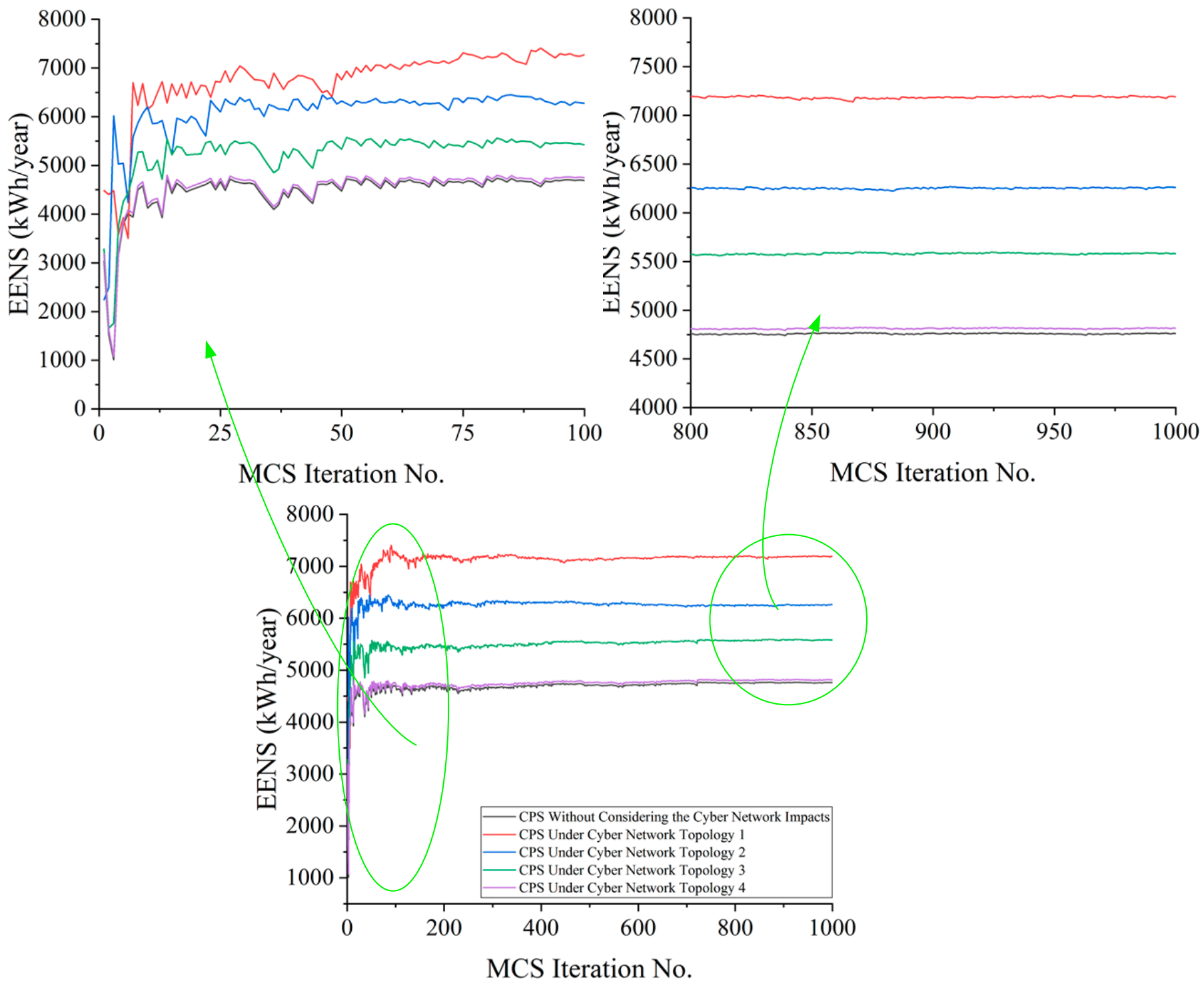

Figure 10. Convergence diagram of the MCS-based reliability evaluation of the CPMG under Scenario 2 and different cyber network topologies.

Test results infer that the CPMG under the first scenario (WT-100) has better reliability indices. The WT generation at all time steps and suitable wind speeds results in better adequacy and reliability indices under Scenarios 1 and 3 compared to Scenario 2 (PV-100). Selecting an appropriate CPMG structure based on studies under different scenarios leads to an improvement in system reliability.

Regardless of the renewable DG scenarios, the most impacts of the cyber network have occurred in Topology 1 without any redundancy. Test results highlight the importance of cyber impacts on CPMG's reliability. The $55.21 \%, 51.24 \%$, and 50.3\% EENS increments have occurred due to the cyber impacts for Topology 1 under scenarios 1, 2, and 3, respectively. It could be concluded that the cyber impacts for Topology 1 are highlighted, while the CPMG reliability and adequacy levels are satisfying (such as Scenario 1) because of the effectiveness of renewable DGs.

Moreover, test results shown in Table 6 imply that the appropriate cyber network (such as cyber network with Topology 4) mitigates the eventual cyber impacts. As revealed by the obtained test results, the cyber impacts under Scenario 1 and Topology 4 have been reduced to $1.5 \%$ compared to $55.21 \%$ (corresponding to Topology 1 ). 


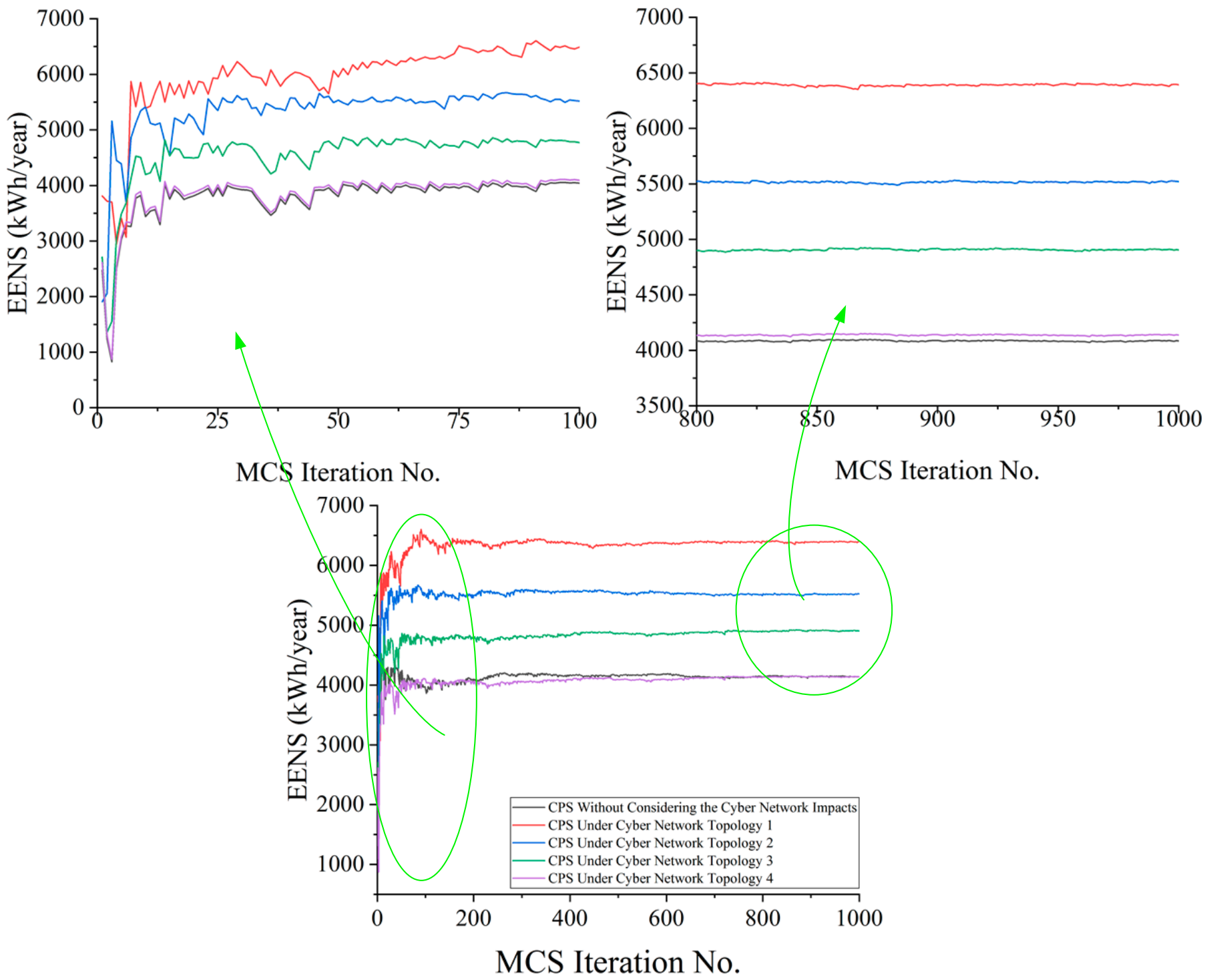

Figure 11. Convergence diagram of the MCS-based reliability evaluation of the CPMG under Scenario 3 and different cyber network topologies.

The EENS increments due to different types of cyber failures and interruptions under various scenarios and topologies are depicted in Figure 12. The EENS value of the CPMG without considering the cyber impacts has been considered the base condition, and the EENS increases due to all cyber impacts under various scenarios have been determined. Finally, the percentage of each cyber impact has been evaluated. The MGCC impacts under all scenarios, while Topologies 1, 2, and 3 have been selected, are significantly affected by other cyber failures and interruptions. In contrast, under Topology 4 of the cyber network with the redundancy of the MGCC, the MGCC failure did not dramatically affect the system reliability. It is therefore concluded that the MGCC failures are important. However, it is possible to mitigate or decrease the negative impacts of MGCC failures on the CPMG reliability by selecting an appropriate cyber network topology.

Another notable result is the EENS increments due to routing errors and information terminal failures. Therefore, it is essential to consider these types of errors and failures in any reliability evaluation of CPMGs that considers different cyber failures and interruptions. 


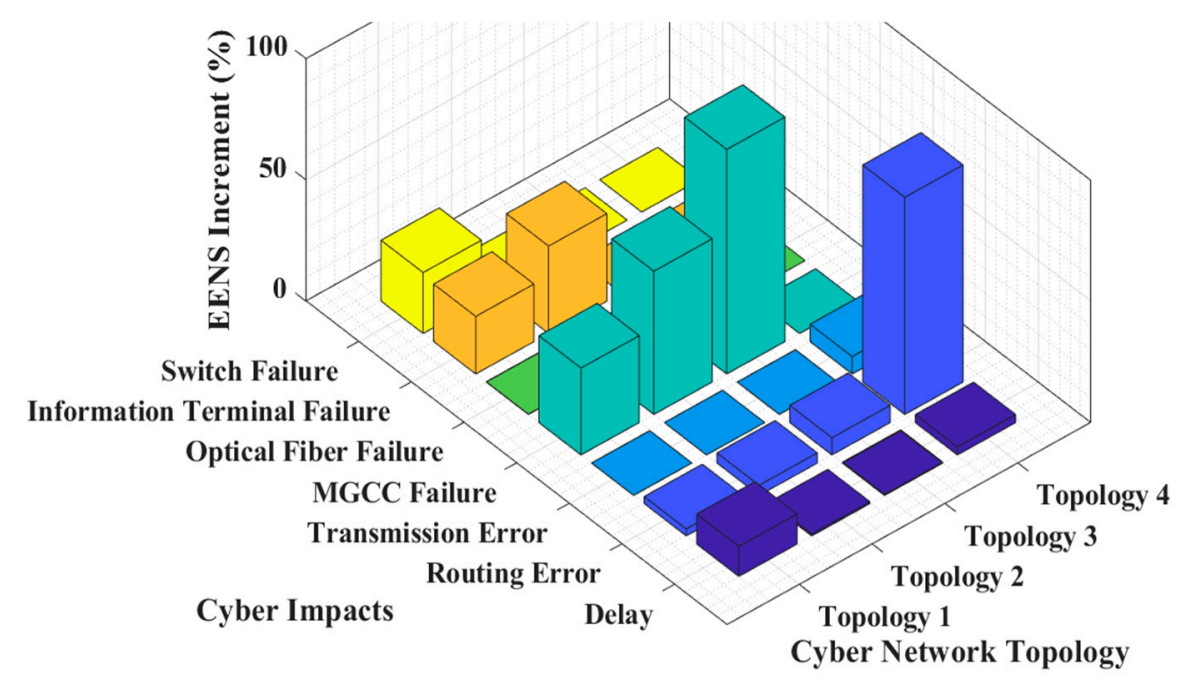

(a) Scenario 1.

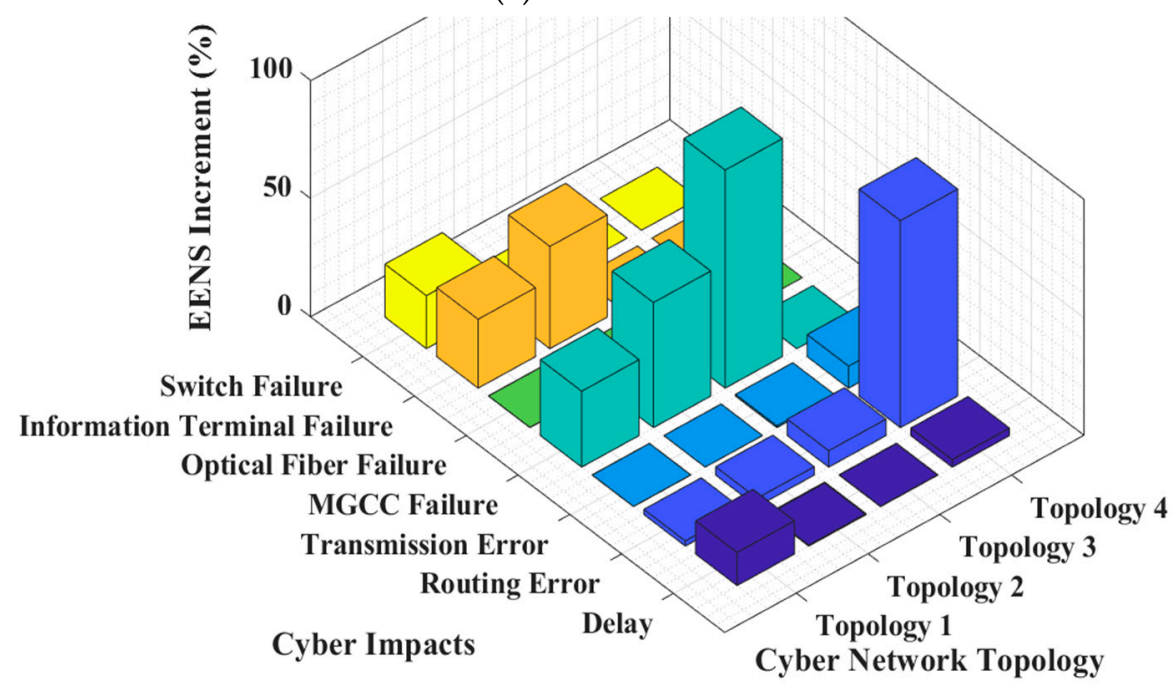

(b) Scenario 2.

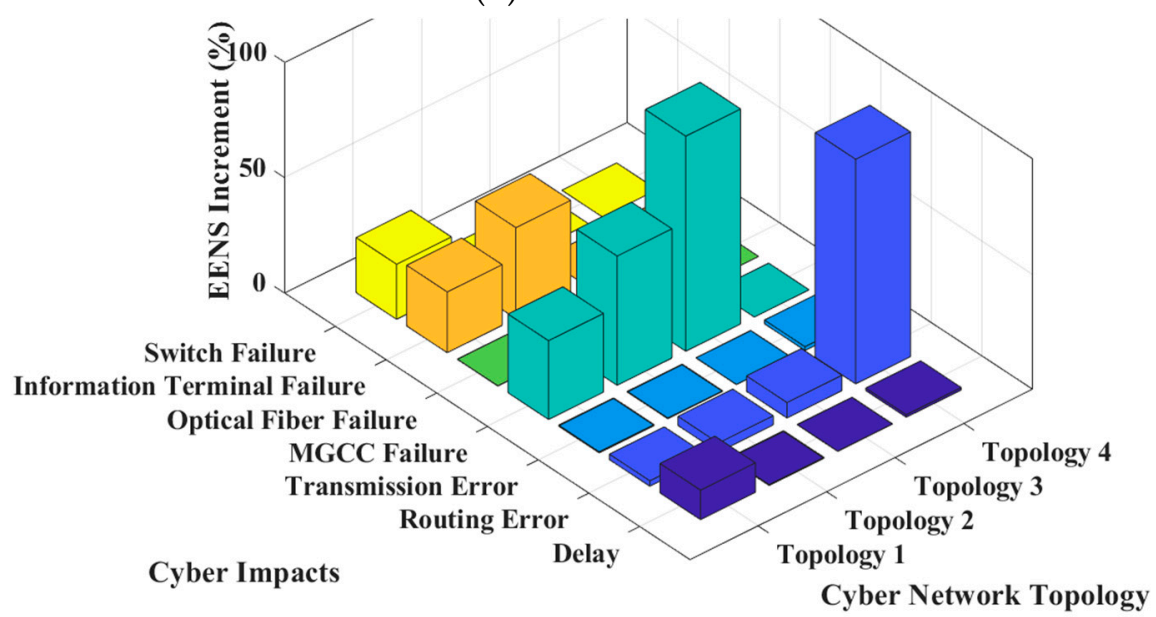

(c) Scenario 3.

Figure 12. Analyses of the EENS increment due to different types of cyber impacts under various scenarios.

In Table 7, to illustrate the EENS decrements that modify the cyber network topologies, the EENS and LOLP increments due to cyber impacts for Topology 1 have been considered 
as the base condition, and the EENS and LOLP decrements for other network topologies compared to Topology 1 have been identified. Comparative test results infer that the cyber network topology affects the CPMG reliability effectively. Regardless of the DG scenarios, approximately $97 \%$ of negative cyber impacts could be omitted using an appropriate cyber network topology, such as Topology 4. The comparison of test results under Topologies 2 and 3 with Topology 4 highlights the importance of the MGCC failures. As observed, the redundancy of the MGCC to mitigate its eventual failures under Topology 4 results in 33\%, $28 \%$, and $35 \%$ EENS improvement.

Table 7. Reliability improvement results of the proposed method under various scenarios and cyber network topologies.

\begin{tabular}{|c|c|c|c|c|c|}
\hline Scenario No. & Topology No. & $\begin{array}{l}\text { EENS Increment Due } \\
\text { to Cyber Impacts } \\
\text { (kWh/Year) }\end{array}$ & $\begin{array}{c}\text { EENS Decrement } \\
\text { Compared to Cyber } \\
\text { Network Topology } 1(\%)\end{array}$ & $\begin{array}{l}\text { LOLP Increment } \\
\text { due to Cyber } \\
\text { Impacts }(\%)\end{array}$ & $\begin{array}{c}\text { Decrement Compared to } \\
\text { Cyber Network } \\
\text { Topology } 1(\%)\end{array}$ \\
\hline \multirow{4}{*}{$\begin{array}{c}\text { Scenario } 1 \\
\text { (WT-100) }\end{array}$} & 1 & 2136.0 & - & 0.5266 & - \\
\hline & 2 & 927.9 & 56.5590 & 0.2927 & 44.4170 \\
\hline & 3 & 758.9 & 64.4710 & 0.1546 & 70.6419 \\
\hline & 4 & 61 & 97.1442 & 0.0295 & 94.3980 \\
\hline \multirow{4}{*}{$\begin{array}{c}\text { Scenario } 2 \\
\text { (PV-100) }\end{array}$} & 1 & 2496.3 & - & 0.5482 & - \\
\hline & 2 & 1280.5 & 48.7041 & 0.3321 & 39.4199 \\
\hline & 3 & 760 & 69.5549 & 0.1539 & 71.9263 \\
\hline & 4 & 62.1 & 97.5123 & 0.0288 & 94.7464 \\
\hline \multirow{4}{*}{$\begin{array}{c}\text { Scenario } 3 \\
\text { (WT-50/PV-50) }\end{array}$} & 1 & 2074.6 & - & 0.5293 & - \\
\hline & 2 & 1300.4 & 37.3180 & 0.3376 & 36.2176 \\
\hline & 3 & 792.6 & 61.7950 & 0.1670 & 68.4489 \\
\hline & 4 & 50.4 & 97.5706 & 0.0351 & 93.3686 \\
\hline
\end{tabular}

To illustrate the contributions of the proposed research, the reliability results of the understudy CPMG that do not consider the MGCC faults, but rather consider other cyber impacts, such as in [16], are presented in Table 8 . The differences in test results based on the proposed method and other available ones (without considering the MGCC faults) have been demonstrated in Table 9. The test results infer that under cyber network topologies 1 , 2 , and 3, considerable inaccuracy occurs in the reliability evaluation of the CPMG without considering the MGCC faults, and the advantages of the proposed method are highlighted. Moreover, the results under Topology 4 show that the impacts of MGCC faults could be completely omitted by selecting an appropriate cyber network.

Table 8. Reliability evaluation results under various scenarios and cyber network topologies without considering the MGCC faults based on available methods such as seen in [16].

\begin{tabular}{ccccc}
\hline & & \multicolumn{3}{c}{ With Cyber Impacts } \\
\cline { 3 - 5 } Scenario No. & Topology No. & $\begin{array}{c}\text { EENS } \\
\text { (kWh/Year) }\end{array}$ & LOLP (\%) & SAIDI (Hour) \\
& & 5277.8 & 1.5145 & 78.007 \\
Scenario 1 & 1 & 4075.4 & 1.2773 & 61.581 \\
(WT-100) & 2 & 3929.5 & 1.151 & 57.656 \\
& 4 & 3929.5 & 1.151 & 57.656 \\
\hline & 1 & 6641 & 1.6132 & 98.393 \\
Scenario 2 & 2 & 5431.3 & 1.3938 & 82.291 \\
(PV-100) & 3 & 4933.8 & 1.2274 & 72.63 \\
& 4 & 4933.8 & 1.2274 & 72.63 \\
\hline \multirow{2}{*}{ Scenario 3 } & 1 & 5481.7 & 1.6476 & 84.682 \\
$($ WT-50/PV-50) & 2 & 4645 & 1.4436 & 70.387 \\
& 3 & 4175.5 & 1.2829 & 62.704 \\
& 4 & 4175.5 & 1.2829 & 62.704 \\
\hline
\end{tabular}


Table 9. Inaccuracies in reliability indices due to MGCC faults under various scenarios and cyber network topologies.

\begin{tabular}{ccccc}
\hline & & \multicolumn{2}{c}{$\begin{array}{c}\text { Inaccuracies in Reliability Indices Due to } \\
\text { Non-Consideration of MGCC Faults }\end{array}$} \\
\cline { 3 - 5 } Scenario No. & Topology No. & $\begin{array}{c}\text { EENS } \\
\text { (kWh/Year) }\end{array}$ & LOLP (\%) & SAIDI (Hour) \\
\cline { 3 - 5 } & & 726.7 & 11.703 & 0.13 \\
Scenario 1 & 1 & 721 & 11.99 & 0.14 \\
(WT-100) & 2 & 697.9 & 10.96 & 0.13 \\
& 3 & 0 & 0 & 0 \\
\hline & 4 & 727 & 11.707 & 0.13 \\
Scenario 2 & 1 & 720.9 & 11.99 & 0.14 \\
(PV-100) & 2 & 697.9 & 10.96 & 0.13 \\
& 3 & 0 & 0 & 0 \\
\hline Scenario 3 & 4 & 718 & 10.841 & 0.13 \\
$($ WT-50/PV-50) & 1 & 780.5 & 11.361 & 0.14 \\
& 2 & 742.2 & 11.562 & 0.13 \\
\hline
\end{tabular}

To further evaluate the impacts of each cyber element's failure on the CPMG reliability, a sensitivity analysis has been performed to obtain insight into how the changes in failures of the cyber elements affect the CPMG reliability, as shown in Figure 13. In this analysis, the failure rates of cyber elements have gradually increased up to ten times under various scenarios.

As revealed by test results shown in Figure 13, regardless of the DG scenarios, the EENS under Topology 1 is very sensitive against the changes in MGCC failure rate. In addition, the switch and information terminal failures could influence the CPMG reliability if they would change. The failure increment of optical fibers under Topology 1 cannot negatively influence the CPMG reliability because its failure rate is very low, and its impacts are negligible compared to other element faults.

As seen, the sensitivity of the CPMG's EENS due to the faults of switches has been solved under Topology 2. However, the changes in the MGCC and information terminal failure rates lead to a significant increment of the CPMG's EENS. Accordingly, it is essential to modify the cyber network topology. Although the sensitivity of the CPMG's EENS due to failures of switches and information terminals has been mitigated under Topology 3 , the MGCC's failure increment might affect the CPMG's EENS. This means that it is not possible to calculate the CPMG's reliability accurately without considering the MGCC faults such as in [16]. Moreover, the test results under Topology 4 emphasize the effectiveness of using an appropriate cyber network topology by the MGCC redundancy.

In order to evaluate the impact of data transmission quality on reliability indices, sensitivity analyses based on changes in the probability of routing errors have been performed, as depicted in Figure 14. As seen, the probability of routing errors has been gradually increased from 0.0001 to 0.001 , and the CPMG's EENS under different cyber network topologies for Scenario 3 (PV and WT-based and hybrid renewable-based DGs) has been assessed.

The test results show that the impacts of routing errors are higher than payload errors under all cyber network topologies. In addition, the EENS increase due to changes in routing and payload errors does not dramatically depend on the cyber network topology.

Furthermore, to evaluate the effect of tolerable latency, a sensitivity analysis has been performed on the CPMG information channel's tolerable latency. In Figure 15, the maximum tolerable latency rate has been gradually increased from 1 to $10 \mathrm{~s}$ under different cyber network topologies and DG scenarios. Test results show that a maximum tolerable latency rate of the information channels higher than $2 \mathrm{~s}$ under Topologies 2, 3, and 4 is satisfactiory. 
However, the impacts of the maximum tolerable latency rate of the information channels on CPMG's reliability are considerable.

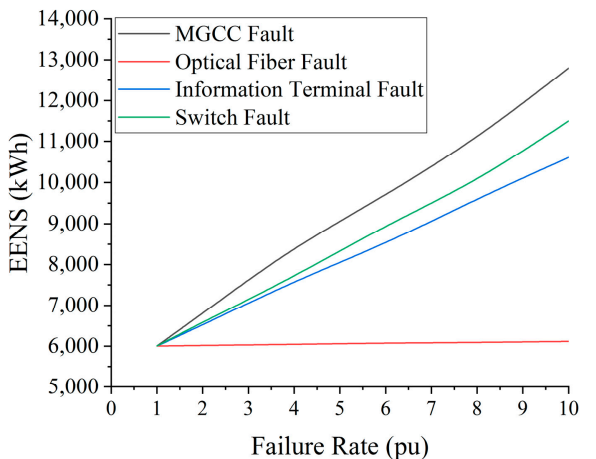

(a) Scenario 1-Topology 1

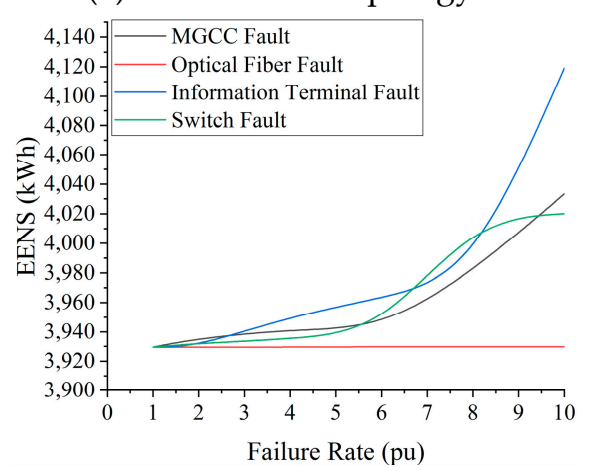

(d) Scenario 1-Topology 4

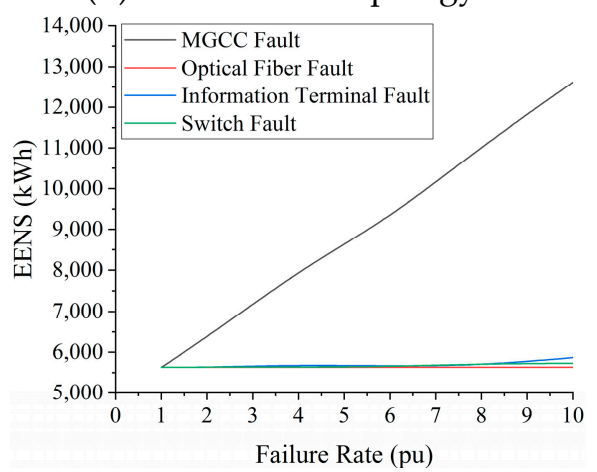

(g) Scenario 2-Topology 3

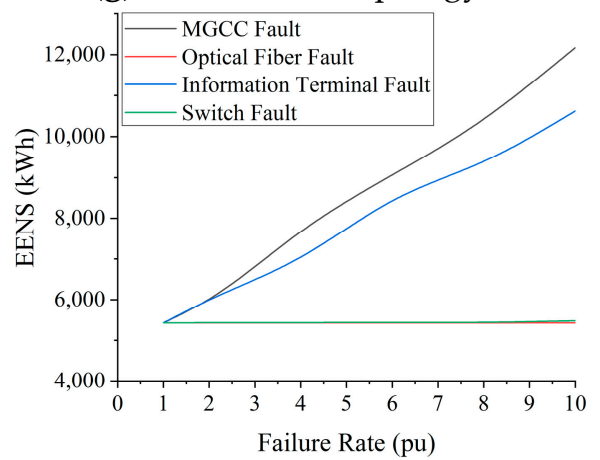

(j) Scenario 3-Topology 2

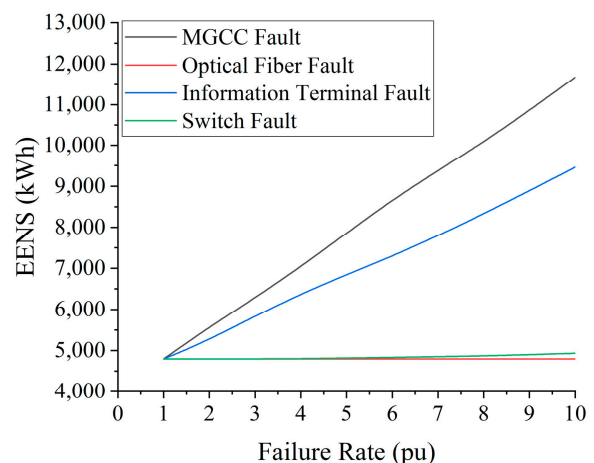

(b) Scenario 1-Topology 2

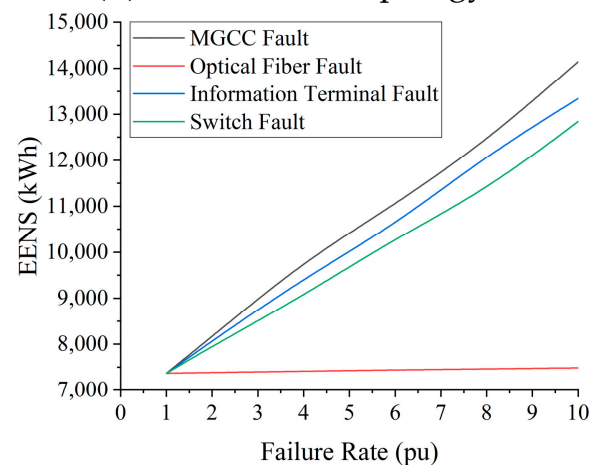

(e) Scenario 2-Topology 1.

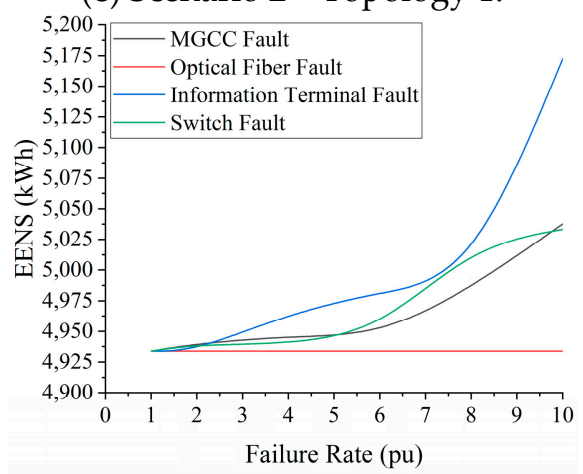

(h) Scenario 2-Topology 4

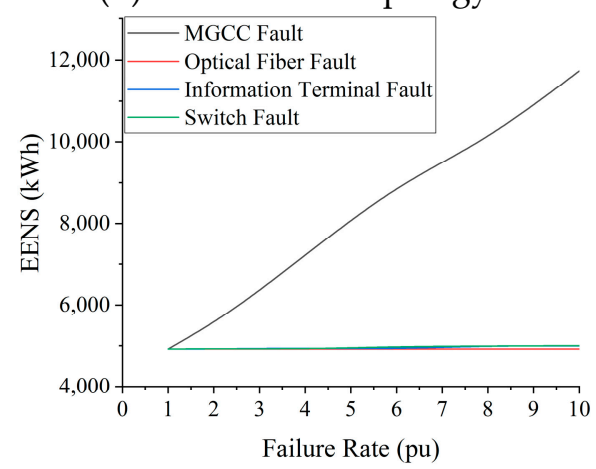

(k) Scenario 3-Topology 3

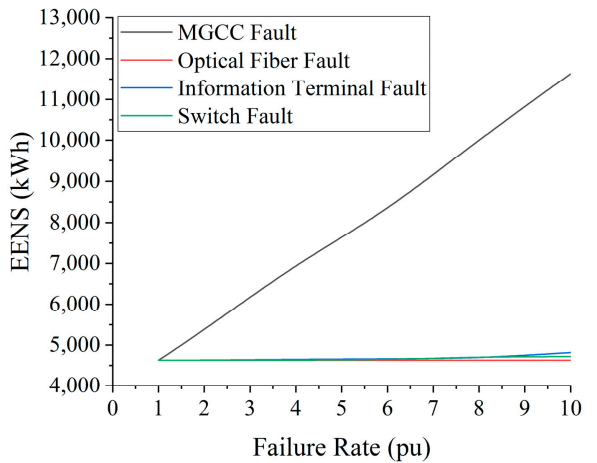

(c) Scenario 1-Topology 3

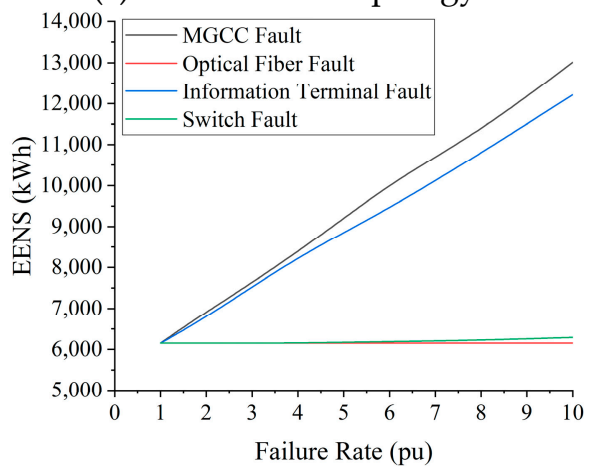

(f) Scenario 2-Topology 2

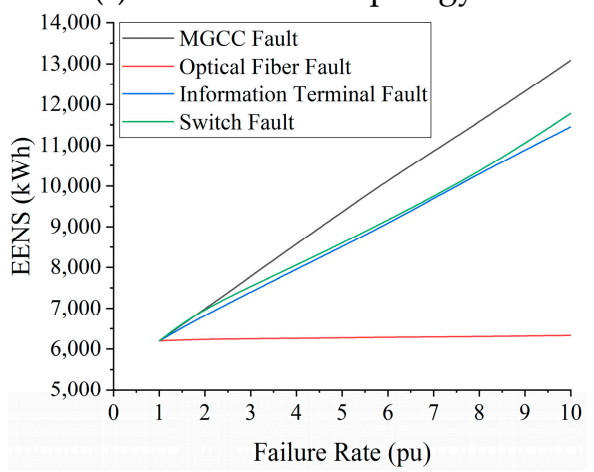

(i) Scenario 3-Topology 1

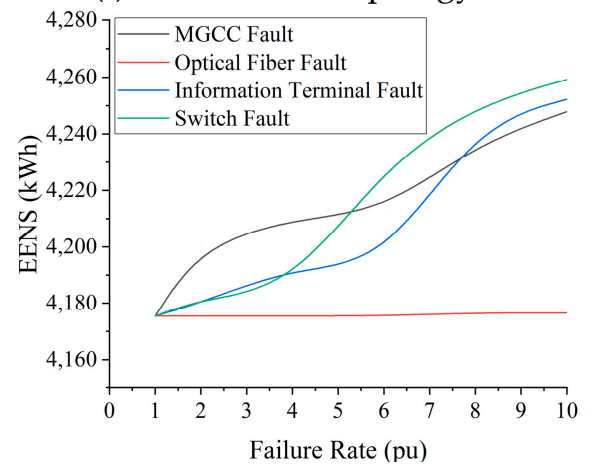

(1) Scenario 3-Topology 4

Figure 13. Sensitivity analyses of EENS via the failure rate of cyber elements under various scenarios and cyber network topologies. 


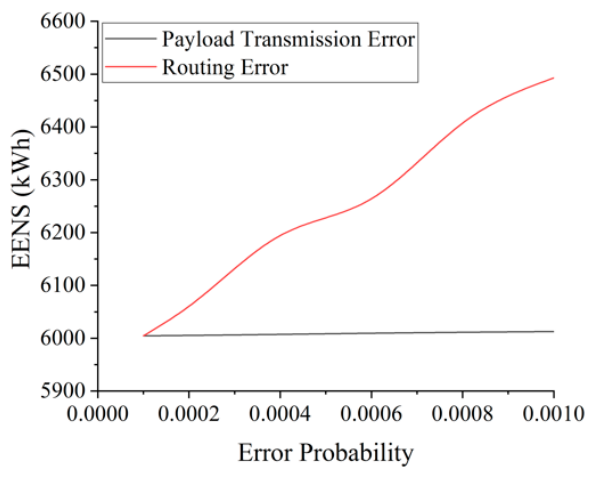

(a) Scenario 1-Topology 1

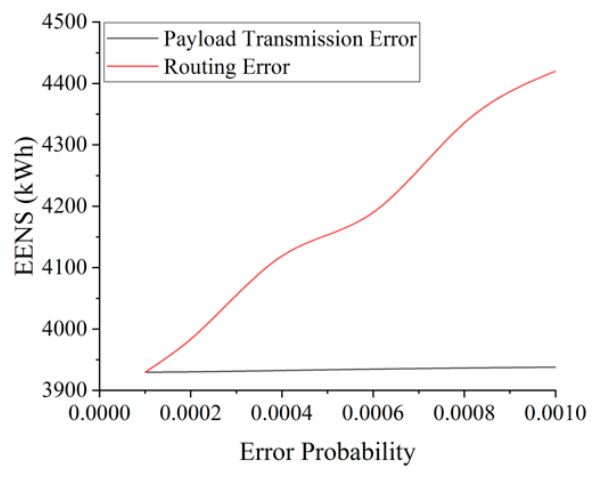

(d) Scenario 1-Topology 4

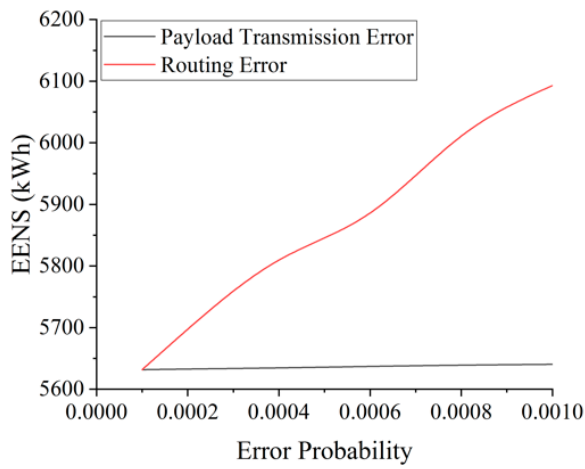

(g) Scenario 2-Topology 3

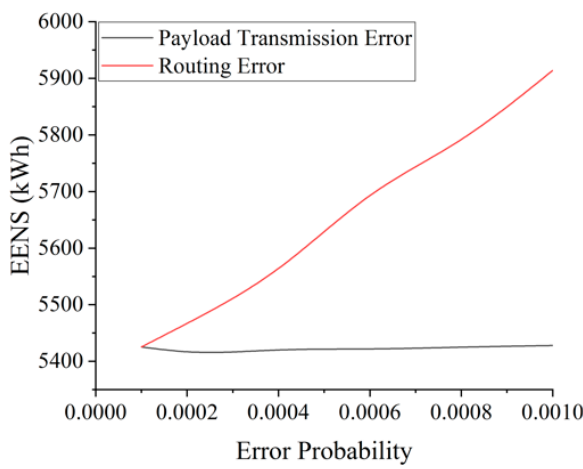

(j) Scenario 3-Topology 2

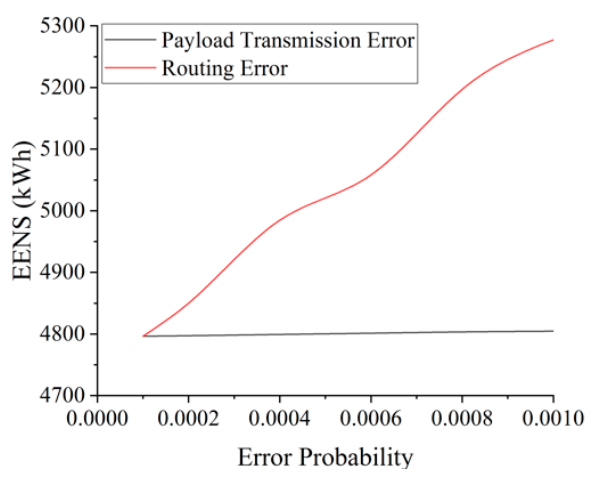

(b) Scenario 1-Topology 2

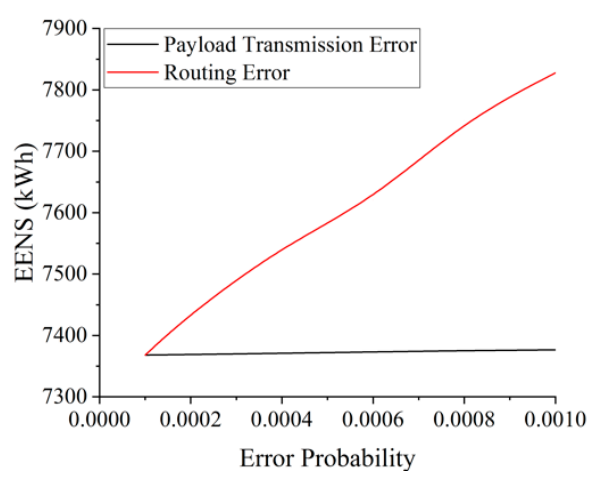

(e) Scenario 2-Topology 1

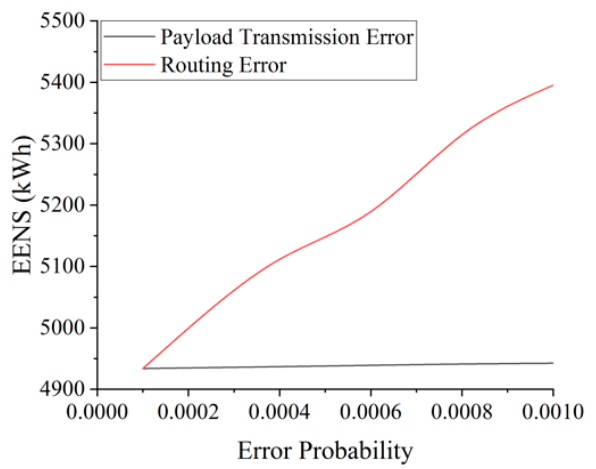

(h) Scenario 2-Topology 4

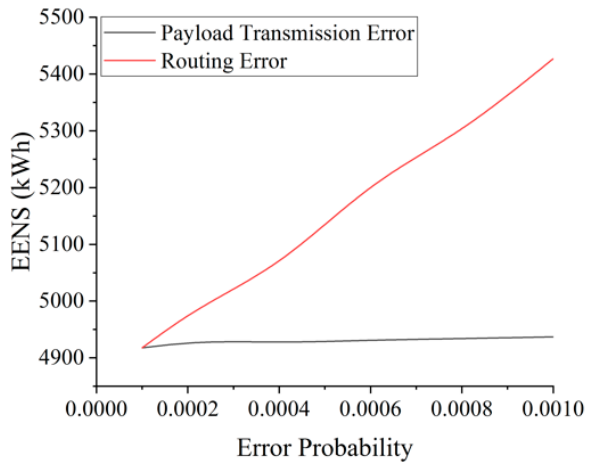

(k) Scenario 3-Topology 3

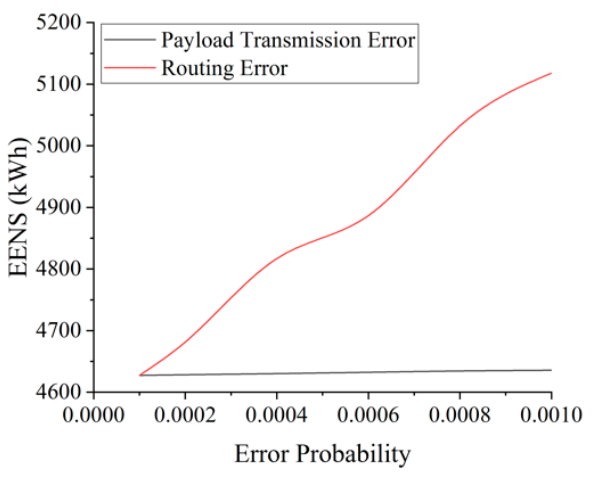

(c) Scenario 1-Topology 3

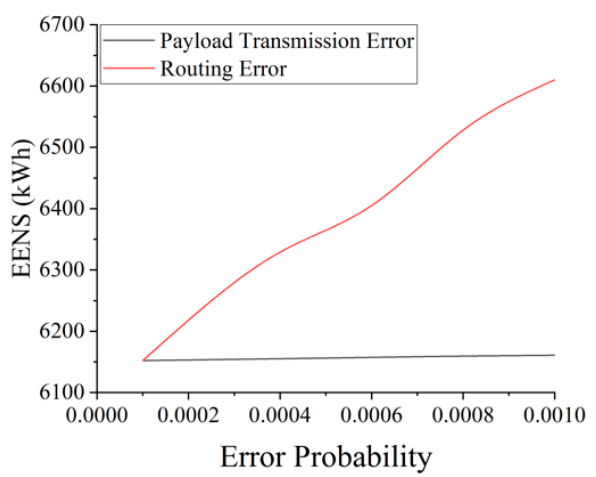

(f) Scenario 2-Topology 2

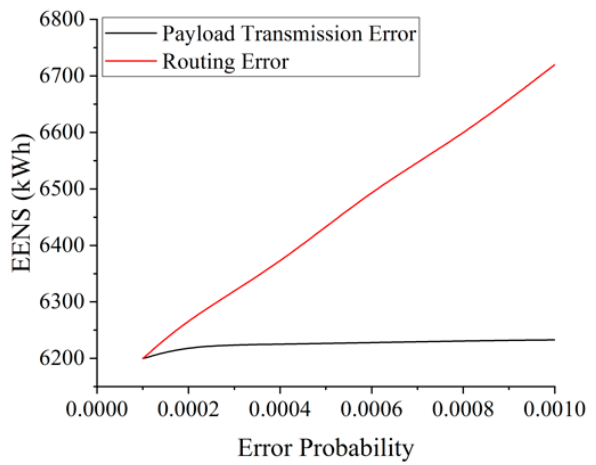

(i) Scenario 3-Topology 1

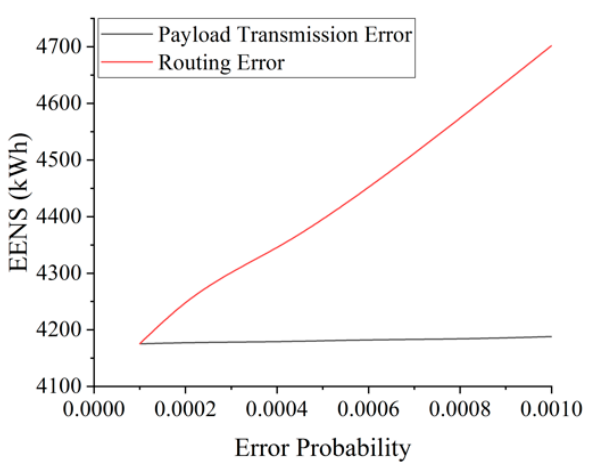

(1) Scenario 3-Topology 4

Figure 14. Sensitivity analyses of EENS via the changes in payload and routing errors under various scenarios and cyber network topologies. 


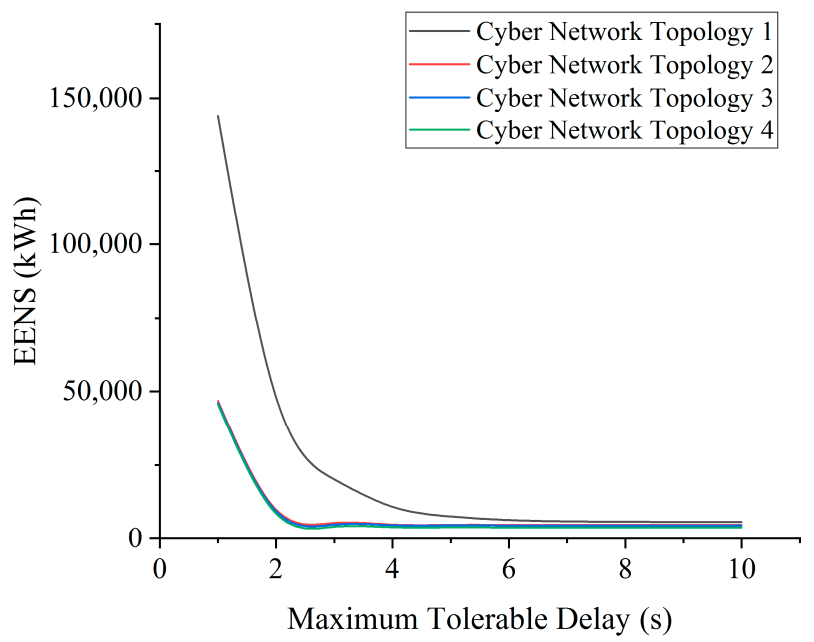

(a) Scenario 1 .

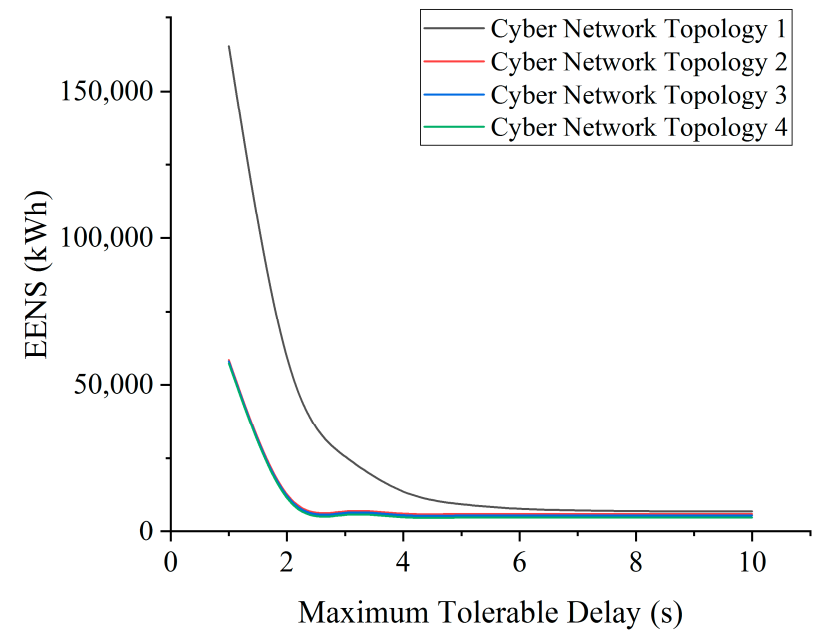

(b) Scenario 2.

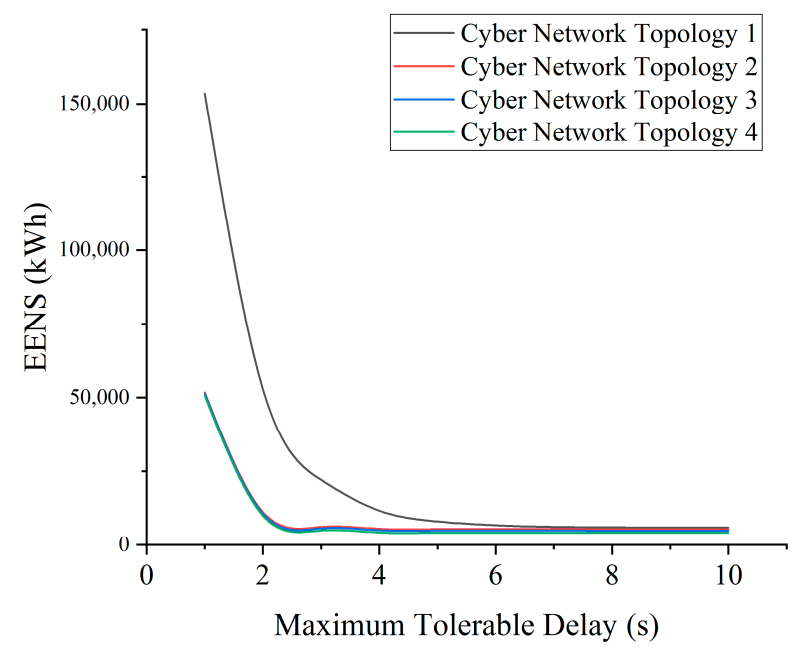

(c) Scenario 3 .

Figure 15. Sensitivity analyses of EENS via the changes in maximum tolerable latency rate of the information channels.

As seen, if it is desired to mitigate the impacts of delays of information channels on the CPMG's reliability, the maximum tolerable latency rate of the information channels should be greater than $6 \mathrm{~s}$ for Topology 1 . Simulation results imply that the impacts 
of the maximum tolerable latency rate of the information channels depend on cyber network topology.

\section{Conclusions}

SMGs have received a great deal of attention in recent years because the advantages of DGs, particularly renewable DGs, are more achievable using SMGs. Although the cyber systems facilitate the energy management schemes in CPMGs, cyber faults, cyber interferences, and cyber-physical interdependencies might affect the CPMG's reliability. A research gap exists in the field of CPMG's reliability evaluation, simultaneously considering all cyber failures and interferences under various cyber network topologies and renewable distributions scenarios. This research tried to fill such a gap by developing a new MCS-based reliability assessment method considering cyber elements' failures, data/information transmission errors, and routing errors under various cyber network topologies. Developing the proposed method by applying the theory graph concepts is one of the contributions of this paper. It should be noted that MGCC faults, aside from other failures and interferences, have been concerned in the proposed method, which is one of the essential contributions of this study. The test results highlighted the advantages of the proposed method considering the MGCC faults' impacts on the CPMG's reliability. It has been concluded based on obtained simulation results that the negative impacts of cyber faults and interruptions could be decreased effectively by selecting an appropriate cyber network topology. The simulation results inferred that the negative impacts of cyberphysical interdependencies could be limited to less than 3\% using a suitable cyber network topology with the redundancy of MGCC.

Author Contributions: Conceptualization, M.A. and H.H.-D.; methodology, M.A. and H.H.-D.; software, M.A. and H.H.-D.; validation, M.A., H.H.-D., and A.K.; formal analysis, H.H.-D. and A.K.; investigation, H.H.-D. and A.K.; resources, H.H.-D. and A.K.; data curation, M.A., H.H.-D., and A.K.; writing—original draft preparation, M.A. and H.H.-D.; writing—review and editing, H.H.-D. and A.K.; visualization, H.H.-D. and A.K.; supervision, H.H.-D. and A.K.; project administration, H.H.-D. and A.K.; funding acquisition, H.H.-D. and A.K. All authors have read and agreed to the published version of the manuscript.

Funding: This research received no external funding.

Institutional Review Board Statement: Not applicable.

Informed Consent Statement: Not applicable.

Data Availability Statement: Not applicable.

Conflicts of Interest: The authors declare no conflict of interest.

\section{Nomenclature}

\section{Indices}

Index of each control cycle time $(t=1: 8760 \times T)$

Index of CPMG's states $\left(i=1: N_{M S}\right)$

Index of physical elements $\left(k=1: N_{P}\right)$

Index of cyber elements $\left(l=1: N_{C}\right)$

Index of generators $\left(l=1: N_{g}\right)$

Index of system elements numbers $\left(j=1: N_{P}+N_{C}\right)$

Index of information channel $\left(f=1: N_{\text {Ich }}\right)$

Index of cyber sender terminal $\left(y=1: N_{C S T}\right)$

Index of cyber receiver terminal $\left(z=1: N_{C R T}\right)$

Index of power sender terminal $\left(q=1: N_{P S T}\right)$

Index of power receiver terminal $\left(r=1: N_{P R T}\right)$ 


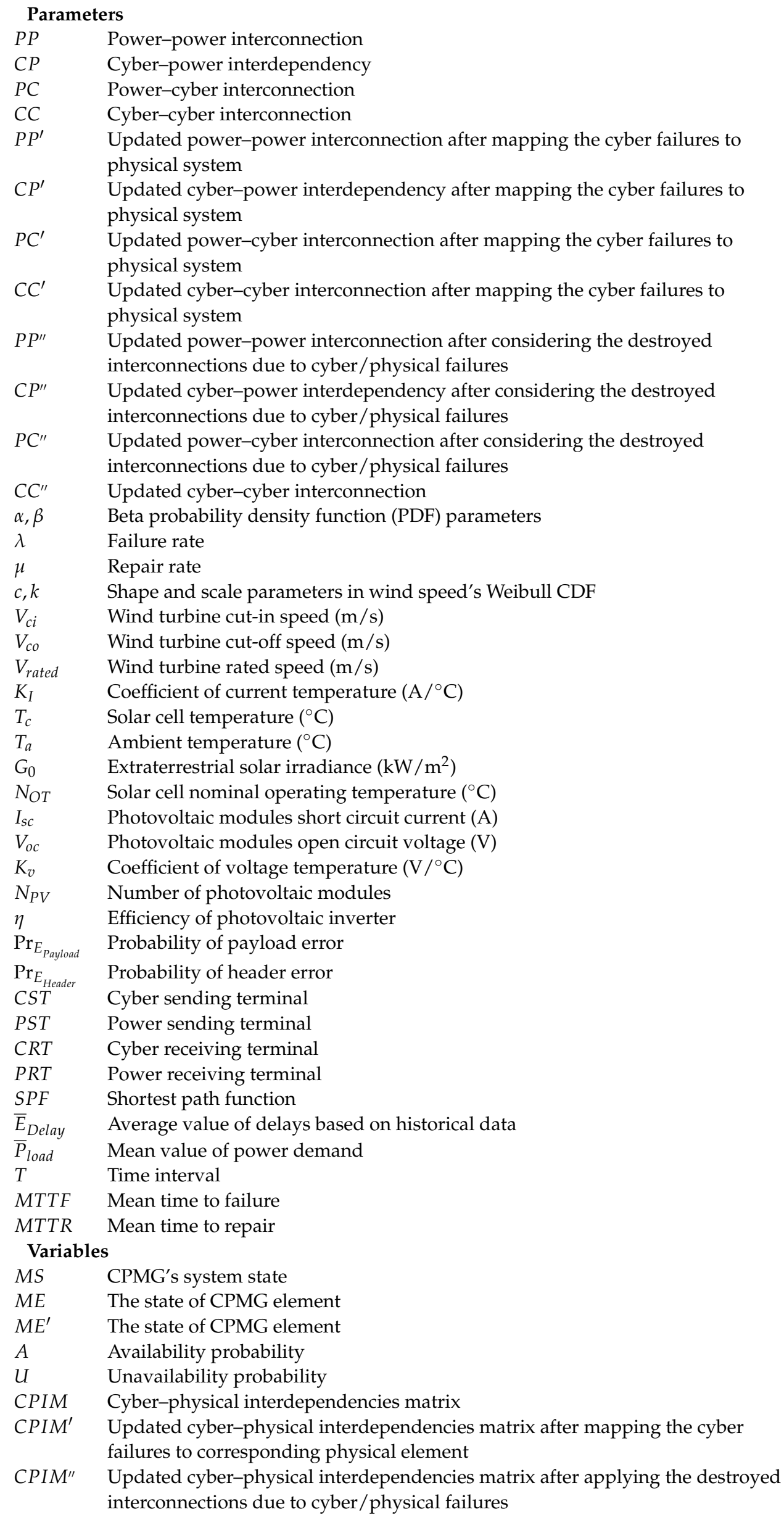




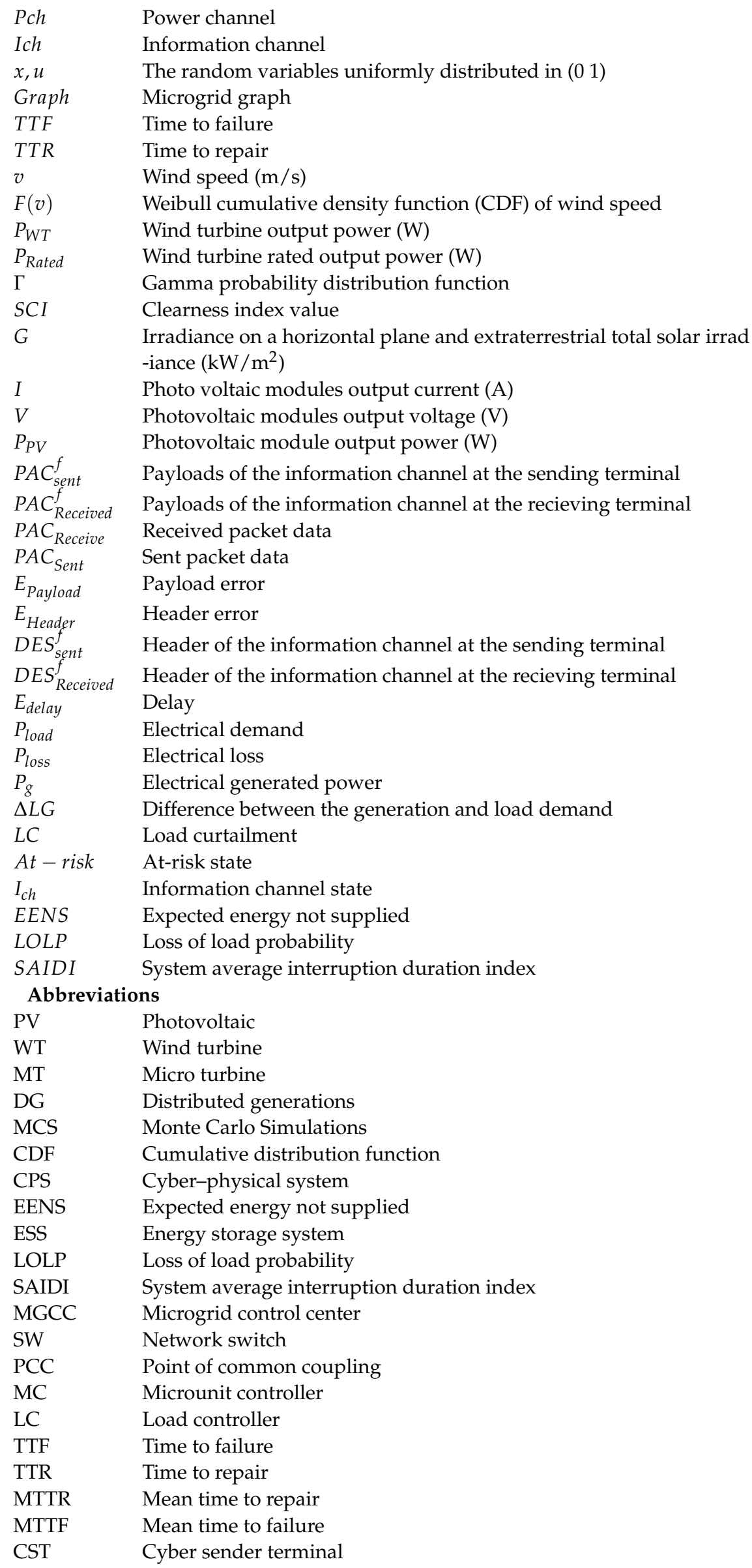




$\begin{array}{ll}\text { CRT } & \text { Cyber receiver terminal } \\ \text { PST } & \text { Power sender terminal } \\ \text { PRT } & \text { Power receiver terminal } \\ \text { SMG } & \text { Smart microgrid } \\ \text { CPMG } & \text { Cyber-power microgrid } \\ \text { P-Table } & \text { Probability table } \\ \text { GWN } & \text { Gaussian white noise } \\ \text { CPIM } & \text { Cyber-physical interdependencies matrix } \\ \text { SPF } & \text { Shortest path function } \\ \text { Pch } & \text { Power channel } \\ \text { Ich } & \text { Information channel }\end{array}$

\section{References}

1. Suman, G.K.; Guerrero, J.M.; Roy, O.P. Optimisation of Solar/Wind/Bio-generator/Diesel/Battery Based Microgrids for Rural Areas: A PSO-GWO Approach. Sustain. Cities Soc. 2021, 67, 102723. [CrossRef]

2. Nasiraghdam, H.; Safari, A. Techno-economic assessment of combined power to hydrogen technology and hydrogen storage in optimal bidding strategy of high renewable units-penetrated microgrids. Sustain. Energy Technol. Assess. 2020, $42,100832$. [CrossRef]

3. Emmanouil, S.; Philhower, J.; Macdonald, S.; Khadim, F.K.; Yang, M.; Atsbeha, E.; Nagireddy, H.; Roach, N.; Holzer, E.; Anagnostou, E.N. A Comprehensive Approach to the Design of a Renewable Energy Microgrid for Rural Ethiopia: The Technical and Social Perspectives. Sustainability 2021, 13, 3974. [CrossRef]

4. Jimada-Ojuolape, B.; Teh, J. Surveys on the reliability impacts of power system cyber-physical layers. Sustain. Cities Soc. 2020, 62, 102384. [CrossRef]

5. Gandhi, I.; Ravi, L.; Vijayakumar, V.; Subramaniyaswamy, V. Improving security for wind energy systems in smart grid applications using digital protection technique. Sustain. Cities Soc. 2020,60, 102265. [CrossRef]

6. Phommixay, S.; Doumbia, M.L.; Cui, Q. A two-stage two-layer optimization approach for economic operation of a microgrid under a planned outage. Sustain. Cities Soc. 2021, 66, 102675. [CrossRef]

7. Mansour-Saatloo, A.; Mirzaei, M.A.; Mohammadi-Ivatloo, B.; Zare, K. A Risk-Averse Hybrid Approach for Optimal Participation of Power-to-Hydrogen Technology-Based Multi-Energy Microgrid in Multi-Energy Markets. Sustain. Cities Soc. 2020, 63, 102421. [CrossRef]

8. Habibzadeh, H.; Nussbaum, B.H.; Anjomshoa, F.; Kantarci, B.; Soyata, T. A survey on cybersecurity, data privacy, and policy issues in cyber-physical system deployments in smart cities. Sustain. Cities Soc. 2019, 50, 101660. [CrossRef]

9. Ding, X.; Guo, Q.; Qiannan, T.; Jermsittiparsert, K. Economic and environmental assessment of multi-energy microgrids under a hybrid optimization technique. Sustain. Cities Soc. 2021, 65, 102630. [CrossRef]

10. Moazeni, F.; Khazaei, J. Optimal operation of water-energy microgrids; a mixed integer linear programming formulation. J. Clean. Prod. 2020, 275, 122776. [CrossRef]

11. Geng, S.; Wu, G.; Tan, C.; Niu, D.; Guo, X. Multi-Objective Optimization of a Microgrid Considering the Uncertainty of Supply and Demand. Sustainability 2021, 13, 1320. [CrossRef]

12. Wang, J.; Gao, X.; Sun, Z. A Multilevel Simulation Method for Time-Variant Reliability Analysis. Sustainability 2021, $13,3646$. [CrossRef]

13. Guo, J.; Zhao, T.; Liu, W.; Zhang, J. Reliability Modeling and Assessment of Isolated Microgrid Considering Influences of Frequency Control. IEEE Access 2019, 7, 50362-50371. [CrossRef]

14. Hashemi-Dezaki, H.; Askarian-Abyaneh, H.; Shams-Ansari, A.; DehghaniSanij, M.; Hejazi, M.A. Direct cyber-power interdependencies-based reliability evaluation of smart grids including wind/solar/diesel distributed generations and plug-in hybrid electrical vehicles. Int. J. Electr. Power Energy Syst. 2017, 93, 1-14. [CrossRef]

15. Hashemi-Dezaki, H.; Agah, S.M.M.; Askarian-Abyaneh, H.; Haeri-Khiavi, H. Sensitivity analysis of smart grids reliability due to indirect cyber-power interdependencies under various DG technologies, DG penetrations, and operation times. Energy Convers. Manag. 2016, 108, 377-391. [CrossRef]

16. Wang, C.; Zhang, T.; Luo, F.; Li, F.; Liu, Y. Impacts of Cyber System on Microgrid Operational Reliability. IEEE Trans. Smart Grid 2019, 10, 105-115. [CrossRef]

17. Falahati, B.; Fu, Y.; Wu, L. Reliability assessment of smart grid considering direct cyber-power interdependencies. IEEE Trans. Smart Grid 2012, 3, 1515-1524. [CrossRef]

18. Falahati, B.; Fu, Y. Reliability assessment of smart grids considering indirect cyber-power interdependencies. IEEE Trans. Smart Grid 2014, 5, 1677-1685. [CrossRef]

19. Zhu, W.; Han, M.; Milanovic, J.V.; Crossley, P. Methodology for Reliability Assessment of Smart Grid Considering Risk of Failure of Communication Architecture. IEEE Trans. Smart Grid 2020, 11, 4358-4365. [CrossRef]

20. Barani, M.; Vadlamudi, V.V.; Heegaard, P.E. Reliability analysis of cyber-physical microgrids: Study of grid-connected microgrids with communication-based control systems. IET Gener. Transm. Distrib. 2020, 15, 645-663. [CrossRef] 
21. Karimipour, H.; Dehghantanha, A.; Parizi, R.M.; Choo, K.K.R.; Leung, H. A Deep and Scalable Unsupervised Machine Learning System for Cyber-Attack Detection in Large-Scale Smart Grids. IEEE Access 2019, 7, 80778-80788. [CrossRef]

22. Stamp, J.; McIntyre, A.; Ricardson, B. Reliability impacts from cyber attack on electric power systems. In Proceedings of the 2009 IEEE/PES Power Systems Conference and Exposition PSCE 2009, Seattle, WA, USA, 15-18 March 2009; pp. 1-8. [CrossRef]

23. Wang, L.; Jiao, S.; Xie, Y.; Mubaarak, S.; Zhang, D.; Liu, J.; Jiang, S.; Zhang, Y.; Li, M. A Permissioned Blockchain-Based Energy Management System for Renewable Energy Microgrids. Sustainability 2021, 13, 1317. [CrossRef]

24. Martinez-Bolaños, J.; Silva, V.; Zucchi, M.; Heideier, R.; Relva, S.; Saidel, M.; Fadigas, E. Performance Analysis of Topologies for Autonomous Hybrid Microgrids in Remote Non-Interconnected Communities in the Amazon Region. Sustainability 2021, 13, 44. [CrossRef]

25. Wu, G.; Li, M.; Li, Z.S. Resilience-Based Optimal Recovery Strategy for Cyber-Physical Power Systems Considering Component Multistate Failures. IEEE Trans. Reliab. 2020, 1-15. [CrossRef]

26. Sadik, S.; Ahmed, M.; Sikos, L.F.; Islam, A.K.M.N. Toward a Sustainable Cybersecurity Ecosystem. Computers 2020, 9 , 74. [CrossRef]

27. Andronie, M.; Lăzăroiu, G.; Iatagan, M.; Hurloiu, I.; Dijmărescu, I. Sustainable Cyber-Physical Production Systems in Big Data-Driven Smart Urban Economy: A Systematic Literature Review. Sustainability 2021, 13, 751. [CrossRef]

28. Wang, Q.; Cai, X.; Tang, Y.; Ni, M. Methods of cyber-attack identification for power systems based on bilateral cyber-physical information. Int. J. Electr. Power Energy Syst. 2021, 125, 106515. [CrossRef]

29. Gao, X.; Peng, M.; Tse, C.K. Cascading Failure A nalysis of Cyber Physical Power Systems Considering Routing Strategy. IEEE Trans. Circuits Syst. II Express Briefs 2021, 1. [CrossRef]

30. Wang, Y.; Nguyen, T.L.; Xu, Y.; Shi, D. Distributed control of heterogeneous energy storage systems in islanded microgrids: Finite-time approach and cyber-physical implementation. Int. J. Electr. Power Energy Syst. 2020, 119, 105898. [CrossRef]

31. Rotar, R.; Jurj, S.L.; Opritoiu, F.; Vladutiu, M. Fault Coverage-Aware Metrics for Evaluating the Reliability Factor of Solar Tracking Systems. Energies 2021, 14, 1074. [CrossRef]

32. Hariri, A.M.; Hashemi-Dezaki, H.; Hejazi, M.A. A novel generalized analytical reliability assessment method of smart grids including renewable and non-renewable distributed generations and plug-in hybrid electric vehicles. Reliab. Eng. Syst. Saf. 2020, 196, 106746. [CrossRef]

33. Park, J.W.; Lee, J.M. Transmission modeling and simulation for Internet-based control. In Proceedings of the IECON'01. 27th Annual Conference of the IEEE Industrial Electronics Society (Cat. No.37243), Denver, CO, USA, 29 November-2 December 2001; Volume 1, pp. 165-169. [CrossRef]

34. Tipsuwan, Y.; Chow, M.Y. Gain scheduler middleware: A methodology to enable existing controllers for networked control and teleoperation-Part I: Networked control. IEEE Trans. Ind. Electron. 2004, 51, 1218-1227. [CrossRef]

35. Rojas, A.J. Feedback control over signal-to-noise ratio constrained communication channels with channel input quantisation. In Proceedings of the 2010 American Control Conference ACC 2010, Baltimore, MD, USA, 30 June-2 July 2010; pp. 265-270. [CrossRef]

36. Xin, S.; Guo, Q.; Sun, H.; Zhang, B.; Wang, J.; Chen, C. Cyber-Physical Modeling and Cyber-Contingency. IEEE Trans. Smart Grid 2015, 6, 2375-2385. [CrossRef]

37. Chehri, A.; Fofana, I.; Yang, X. Security Risk Modeling in Smart Grid Critical Infrastructures in the Era of Big Data and Artificial Intelligence. Sustainability 2021, 13, 3196. [CrossRef]

38. Zhao, S.; Yan, X.; Wang, B.; Wang, E.; Ma, L. Research on reliability evaluation method of DC circuit breaker based on Markov model. Electr. Power Syst. Res. 2019, 173, 1-5. [CrossRef]

39. Hariri, A.-M.; Hejazi, M.A.; Hashemi-Dezaki, H. Investigation of impacts of plug-in hybrid electric vehicles' stochastic characteristics modeling on smart grid reliability under different charging scenarios. J. Clean. Prod. 2021, 287, 125500. [CrossRef]

40. Blokus, A.; Dziula, P. Relations of Imperfect Repairs to Critical Infrastructure Maintenance Costs. Sustainability $2021,13,4917$. [CrossRef]

41. Kim, W.; Eom, H.; Kwon, Y. Optimal Design of Photovoltaic Connected Energy Storage System Using Markov Chain Models. Sustainability 2021, 13, 3837. [CrossRef]

42. Hashemi-Dezaki, H.; Hariri, A.-M.; Hejazi, M.A. Impacts of load modeling on generalized analytical reliability assessment of smart grid under various penetration levels of wind/solar/non-renewable distributed generations. Sustain. Energy Grids Netw. 2019, 20, 1-16. [CrossRef]

43. Arya, L.D.; Choube, S.C.; Arya, R.; Tiwary, A. Evaluation of reliability indices accounting omission of random repair time for distribution systems using Monte Carlo simulation. Int. J. Electr. Power Energy Syst. 2012, 42, 533-541. [CrossRef]

44. Bellavista, P.; Giannelli, C.; Mamei, M.; Mendula, M.; Picone, M. Application-driven Network-aware Digital Twin Management in Industrial Edge Environments. IEEE Trans. Ind. Inform. 2021, 1. [CrossRef]

45. Song, J.; Lee, Y.; Choi, J.-W.; Gil, J.-M.; Han, J.; Choi, S.-S. Practical In-Depth Analysis of IDS Alerts for Tracing and Identifying Potential Attackers on Darknet. Sustainability 2017, 9, 262. [CrossRef]

46. Vahid-Pakdel, M.J.; Nojavan, S.; Mohammadi-ivatloo, B.; Zare, K. Stochastic optimization of energy hub operation with consideration of thermal energy market and demand response. Energy Convers. Manag. 2017, 145, 117-128. [CrossRef] 
47. Hashemi-Dezaki, H.; Hamzeh, M.; Askarian-Abyaneh, H.; Haeri-Khiavi, H. Risk management of smart grids based on managed charging of PHEVs and vehicle-to-grid strategy using Monte Carlo simulation. Energy Convers. Manag. 2015, 100, 262-276. [CrossRef]

48. Faraji, J.; Hashemi-Dezaki, H.; Ketabi, A. Optimal probabilistic scenario-based operation and scheduling of prosumer microgrids considering uncertainties of renewable energy sources. Energy Sci. Eng. 2020, 8, 3942-3960. [CrossRef]

49. Yona, A.; Senjyu, T.; Funabashi, T. Application of Recurrent Neural Network to Short-Term-Ahead Generating Power Forecasting for Photovoltaic System. In Proceedings of the 2007 IEEE Power Engineering Society General Meeting, Tampa, FL, USA, 24-28 June 2007; pp. 1-6.

50. Memari, M.; Karimi, A.; Hashemi-Dezaki, H. Reliability evaluation of active distribution networks based on scenario reduction method using PSO algorithm. In Proceedings of the 2020 10th Smart Grid Conference (SGC), Kashan, Iran, 16-17 December 2020; pp. 1-6.

51. Available online: http:/ / www.satba.gov.ir (accessed on 17 May 2021).

52. Kounev, V.; Tipper, D.; Yavuz, A.A.; Grainger, B.M.; Reed, G.F. A Secure Communication Architecture for Distributed Microgrid Control. IEEE Trans. Smart Grid 2015, 6, 2484-2492. [CrossRef]

53. Zheng, L.; Parkinson, S.; Wang, D.; Cai, L.; Crawford, C. Energy efficient communication networks design for demand response in smart grid. In Proceedings of the 2011 International Conference on Wireless Communications and Signal Processing (WCSP), Nanjing, China, 9-11 November 2011. [CrossRef]

54. Shafiee, Q.; Guerrero, J.M.; Vasquez, J.C. Distributed secondary control for islanded microgrids-a novel approach. IEEE Trans. Power Electron. 2014, 29, 1018-1031. [CrossRef]

55. Wang, Y.; Li, W.; Lu, J.; Liu, H. Evaluating multiple reliability indices of regional networks in wide area measurement system. Electr. Power Syst. Res. 2009, 79, 1353-1359. [CrossRef]

56. Wang, Y.; Li, W.; Lu, J. Reliability analysis of phasor measurement unit using hierarchical markov modeling. Electr. Power Compon. Syst. 2009, 37, 517-532. [CrossRef] 